\title{
Einführung in den Band, samt eines Versuchs über die Frage, ob Europa als, Wissensraum'verstanden werden kann
}

\author{
Ulrike Haß
}

\section{Ziele des Bandes}

Dieses Buch porträtiert ,große‘ Nachschlagewerke als Meilensteine der europäischen Kultur- und Wissensgeschichte und zeigt heutigen Leserinnen und Lesern die Zugänge zum Informationspotenzial der wichtigsten europäischen Lexika. Die stark beschränkende Auswahl auf weniger als 30 Werke in 26 Beiträgen erfordert eine Reihe von Auswahlkriterien, die zunächst erläutert werden sollen.

Unter Lexikon werden hier zunächst im allgemeinen, weiteren Sinne sowohl solche zu den Wörtern einer Sprache, d.h. Wörterbücher (dictionaries, dictionnaires), als auch solche zu den Dingen einer Kultur, d.h. Enzyklopädien (Lexika im engeren Sinne, lexicons, encyclopedias, encyclopédies) verstanden.

Es scheint, dass in nordeuropäischen Kulturen Wörterbücher und Enzyklopädien stärker unterschiedene Textmuster ausgebildet haben als in der Romania, wo Mischformen bzw. konvergente Textmuster sehr populär sind. Dies zeigt schon allein der genaue Titel der großen französischen Enzyklopädie des 18. Jahrhunderts: Encyclopédie ou dictionnaire raisonnée ... Das ou (oder), kein et (und) verbindet hier beide offenbar doch unterschiedlich begriffenen Gattungen. Die anhaltende Popularität von Mischformen, bei denen sprachliches Wissen in eine Enzyklopädie integriert wird und nicht umgekehrt, zeigt heute die Enciclopedia Italiana (vgl. Schafroth in diesem Band).

Wörterbücher sind sprachbezogene Nachschlagewerke; Enzyklopädien oder enzyklopädische Lexika sind sachbezogene Nachschlagewerke. Da jede wissenswerte ,Sache' mit (mindestens) einem sprachlichen Ausdruck verbunden ist, so wie z. B. die Tierart der Delfine mit dem in zwei orthografischen Varianten vorliegenden Wort Delfin/Delphin verknüpft ist, unterscheiden viele Nutzerinnen und Nutzer meistens nicht zwischen Wörterbüchern und Lexika. Aus diesem Grunde sind auch Vertreter beider Typen von Nachschlagewerken in diesen Band aufgenommen worden. Dennoch kann man Wörterbücher als Nachschlagewerke zu Bedeu- 
tung und Gebrauch der Wörter einer Sprache recht gut von Enzyklopädien als Nachschlagewerken zu Dingen, Personen, Orten, Sachverhalten und Vorstellungen unterscheiden. Ein erstes und oberflächliches Unterscheidungsmerkmal ist die Art der Stichwörter: In einem Wörterbuch sind normalerweise sämtliche Wortarten vertreten - neben Substantiven auch Verben, Adjektive, Adverbien, Artikelwörter, Pronomen, Partikeln, Junktoren usw., nicht jedoch Namen von Personen, Ländern und Orten, es sei denn, sie wären aus sprachlichen Gründen interessant oder schwierig. In einem sachbezogenen Lexikon hingegen findet man neben Substantiven nur wenige Adjektive und Verben, aber keine anderen Wortarten. Dafür sind Personen, Länder, Orte mit ihren Bezeichnungen vertreten. Wenn ein Sachlexikon über die verschiedenen Arten von Fröschen informieren will, steht das Stichwort entsprechend im Plural (Frösche), wohingegen in einem Sprach-Wörterbuch immer die Normalform der Wörter (üblicherweise Nominativ Singular bzw. Infinitiv) angesetzt ist (Frosch, der).

Der vorliegende Band enthält Porträts zu neunzehn Wörterbüchern bzw. Wörterbuchfamilien und zu sieben Enzyklopädien. Es handelt sich hierbei lediglich um einen aus lexikografischer Sicht angelegten Versuch, beide Texttraditionen in einen Zusammenhang zu bringen. Es gibt zahlreiche einzelne Belege dafür, dass Wörterbuchschreiber bei ihrer Arbeit auf Enzyklopädien und Enzyklopädisten auf Wörterbücher zurückgegriffen haben. Die Enzyklopädistik, verstanden als die Wissenschaft von der Erforschung enzyklopädischer Nachschlagewerke, nahm ihren Ausgang m. W. in der Geschichtswissenschaft, aber auch Sprachhistoriker, Mediävisten und Philologen haben begründetes Interesse an der Quellengattung Enzyklopädie (Eybl et al. 1995; Stammen/Weber 2004, Schneider 2008). Zugleich ist über die Enzyklopädien nicht weniger Länder und Kulturen zu wenig bekannt, um sie in diesem Band berücksichtigen zu können. ${ }^{1}$

Aus der Fülle von Sprach-Wörterbüchern werden hier nur einsprachige bedeutungserklärende Wörterbücher der jeweiligen Gesamt- bzw. Standardsprache ausgewählt. Die herausgehobene und historisch zentrale Stellung dieser Gruppe ist aus sprachwissenschaftlicher Sicht unstrittig. Sie gingen in aller Regel den zweisprachigen Wörterbüchern, den Mundart-, Fach- und Sondersprachenwörterbüchern voran. Die Bedeutung der Wörter anzugeben gilt als die wichtigste Aufgabe eines Wörterbuchs; daher stellen alle jene Wörterbücher (hier nicht zu behandelnde) Sonderfälle dar, die sich auf eine der sonstigen Informationen zu einem Wort beschränken: Rechtschreibwörterbücher sowie etymologische oder Herkunftswörterbücher. Ausgeschlossen wurden auch Wörterbücher, die nur einen Teil des standardsprachlichen Wortschatzes, z. B. nur Phraseologismen, nur Lernerwortschatz, nur Fachwortschatz, nur Verben usw. behandeln. Für manche LeserInnen mag der Hinweis wichtig sein, dass sog. Fremdwörter nicht auf Fach-

\footnotetext{
1 Dies scheint z. B. für die skandinavischen Länder zuzutreffen, wie mir Sven Göran Malmgren freundlicherweise bestätigte.
} 
wortschatz beschränkt sind und daher auch keinen sondersprachlichen Wortschatz darstellen. D.h., dass die Konzentration auf ,einsprachige bedeutungserklärende Wörterbücher der jeweiligen Gesamt- bzw. Standardsprache` Fremd- und Lehnwörter einbezieht. ${ }^{2}$

Dieser Band weicht an zwei Stellen von diesem Auswahlprinzip ab, als auch zwei Synonymiken aufgenommen sind: Rogets English Thesaurus und Dornseiffs Wortschatz nach Sachgruppen. Es handelt sich bei Synonymiken um Wörterbücher, die den Wortschatz nach begrifflich-konzeptuellen Aspekten oder nach den bezeichneten Sachen und damit außersprachlich anordnen, so dass Bedeutungsrelationen, v.a. Ober- und Unterbegriffsrelationen sowie synonymische Beziehungen zwischen den Wörtern augenfällig werden. Auf diese Weise entstehen Nachschlagewerke, die zwar nur von Muttersprachlern gut nutzbar sind, aber bei der stilistischen Optimierung und bei der genauen Wortfindung helfen. Darüber hinaus sind sie als Versuche, die in Worten fassbare, Welt' systematisch zu ordnen, den frühen Enzyklopädien ähnlich. Bis in die Zeit der Frühaufklärung hinein waren Enzyklopädien i.d.R. nicht alphabetisch, sondern nach der (vermeintlichen) Ordnung der ,Sachen ' und Wissensinhalte angeordnet. Sie orientierten sich dabei lange Zeit am Curriculum der sieben freien Künste (septem artes liberales). Damit korrespondierte die vormoderne Auffassung der Identität bzw. unmittelbaren Abbildlichkeit von Wort und Ding (vgl. Gardt 1999: 94ff.), die in historischer Perspektive eine strikte Trennung von Sachlexikon und Sprachwörterbuch schwierig macht. Welt und Wortschatz waren quasi vorgegebene und vom Menschen unabhängige Ordnungen. In der Aufklärung, die die vermittelnde und wesentliche Rolle von Erfahrung und Wahrnehmung ,entdeckte‘, musste das fraglose Gebäude des Wissens ins Wanken geraten, sodass das sinn-lose Alphabet als einzig mögliches Anordnungskriterium die Oberhand gewann. Man kann die Synonymiken von Roget für das Englische und Dornseiff für das Deutsche also als moderne Versuche interpretieren, die in der Aufklärung zerbrochene Idee einer sinnvollen und der Welt (nicht der Sprache) entnommen Ordnung des Wortschatzes auf neue Art wiederherzustellen. Dornseiff und v.a. Roget erfüllen zudem das Auswahlkriterium der öffentlichen Sichtbarkeit und gesellschaftlichen Relevanz (s.u.) in besonderem Maße; außerdem sind beide wiederum exemplarische Bezugspunkte für europäische Querverbindungen.

In der Menge der Sachlexika sind ähnlich wie bei den Sprachwörterbüchern Gruppen zu unterscheiden; hier ragt die Gruppe der universalen Lexika, die alle in einer Kultur für relevant gehaltenen Wissensgebiete abdecken, heraus. Viele Bücher, die die Bezeichnung Enzyklopädie im Titel tragen (z. B. Enzyklopädie der Gar-

2 Die Sprachwissenschaft unterscheidet zwischen Lehnwörtern, die aus einer anderen Sprache übernommen, aber aufgrund langen Gebrauchs in ihrer Form und in ihrem Inhalt ganz in die aufnehmende Sprache integriert, ,eingebürgert', sind, wohingegen Fremdwörter diesen Integrationsprozess nur teilweise oder noch gar nicht durchlaufen haben; bei häufigem Gebrauch werden aus Fremdwörtern meist Lehnwörter. 
tenpflanzen, Enzyklopädie der Astronomie), sind keine, wenn man die historische Grundbedeutung dieses Worts zugrundelegte. Um deutlich zu machen, dass Kulturen nicht mit einer Sprache und einer Staatsnation zusammenfallen müssen und dass solche Kulturen sogar ein besonderes Interesse an einer enzyklopädisch hergestellten Identität haben können, wurde exemplarisch die Enzyklopädie der Ukrainekunde aufgenommen. Daneben müsste ein Beitrag über die Große Sowjetische Enzyklopädie, begonnen in den 1920er Jahren und nach dem Ende der Sowjetunion als Große Russische Enzyklopädie in neuer Bearbeitung erschienen, stehen; ein solcher Beitrag ließ sich derzeit noch nicht realisieren. Ein anders gelagerter, interessanter, aber nicht berücksichtigter Fall ist die Enzyklopädik der Schweiz, die als Exil- und Asylland zur Produktionsstätte von Universal-Enzyklopädien anderer europäischer Kulturen wurde (Jorio 2004).

Eine auf wesentlicheren Aspekten als auf den o.g. Äußerlichkeiten, nämlich auf ihren kulturellen Funktionen fußende Unterscheidung zwischen Wörterbuch und Sachlexikon gelingt umso besser, je mehr man beides als Textsorten mit je eigener Geschichte und Tradition sehen lernt. Als ich mein Buch über die Geschichte der deutschsprachigen Wörterbücher (Haß-Zumkehr 2001) schrieb, wurde mir immer wieder bewusst, dass sich die Traditionen der Wörterbücher, aber auch die der damals von mir nur gestreiften Sachlexika nicht in den Grenzen einer Nation oder einer Nationalsprache halten lassen. Selbst in den Epochen stärkeren Nationalbewusstseins haben sich die Lexikografen und Enzyklopädisten nicht um die ansonsten umkämpften nationalen Grenzen geschert, sondern sie haben sich technisch-methodisch, sprachtheoretisch, philosophisch und ideologisch ganz selbstverständlich in einem viel größeren intellektuellen Raum bewegt, haben einander nachgeahmt, Anleihen gemacht, Gegenpositionen formuliert und auf einander aufgebaut. Da stellt sich die Frage, ob dieser intellektuelle Raum, in dem riesige Informationssammlungen zur Bildung von Wissen durch Individuen und Gesamtgesellschaft aufbereitet wurden und werden, in irgendeiner Weise mit dem ,geistigen Europa' zur Deckung kommt und ob eine Zusammenschau wenigstens der ,großen' und einflussreichsten Nachschlagewerke Europas die Antwort auf diese Frage erleichtern könnte.

\section{Zur geographischen, relevanzbezogenen und zeitlichen Rahmung}

Wahrscheinlich ist auch ,Europa' noch zu eng gewählt. Die Beschränkung dieses Bandes auf Europa ist zunächst pragmatisch begründet: mit Rücksicht auf den Umfang eines ,Einbänders' und mit Rücksicht darauf, dass wohl niemand die Lexika ,der Welt’ dergestalt überblickt, dass er eine repräsentative Auswahl auch asiatischer, afrikanischer und weiterer Kulturräume treffen könnte. Immerhin ist auch die Öffnung der mehr oder weniger national angelegten Sprach-, Wissenschafts- und Kulturgeschichten auf Europa hin erst wenige Jahrzehnte alt und immer noch gibt es hier viele Lücken im Kenntnisstand, zu deren Schließung dieser Band beitragen 
möchte. Die z.T. knappen Darstellungen zur arabischen und chinesischen Lexikografie, die in englischer oder deutscher Sprache zugänglich sind (Creamer 1991, Haywood 1991, Heming Yong/Jing Peng 2008), zeigen immerhin, dass es offenbar auch weltweite Gemeinsamkeiten gibt. Dazu zählt, dass Sprachlexikografie in jeweils frühen Stadien der Ausbildung in Schriftlichkeit und - jeweils etwas später regelmäßig der Standardisierung einer bestimmten Varietät dient. Dazu zählt auch, dass die Anordnungsweisen der Stichwörter in erster Linie von Eigenschaften des Schriftsystems abhängen; nicht-phonetische Schriften wie das Chinesische tendieren zu begrifflich-semantischen Anordnungsweisen, obwohl in jüngerer Zeit auch formale Eigenschaften der Schriftzeichen zugrundgelegt wurden (Creamer 1991). Dass Nachschlagewerke der arabischen Welt oft nach Wortwurzeln, bestehend aus wenigen Konsonantenzeichen, angeordnet werden, hat mit einer morphologischen Eigenschaft der semitischen Sprachenfamilie zu tun (Haywood 1991). Hingegen stellt die Tatsache, dass es zwar viele kleinere, spezialisiertere arabische Nachschlagewerke, aber kaum große Referenzwerke gibt, eine kulturelle Eigenschaft dar (ebd.). Andererseits veränderten sowohl arabische als auch chinesische Nachschlagewerke ihre Methodik unter jüngerem europäischem Einfluss wie auch umgekehrt die arabische Lexikografie v.a. in Mittelalter und Früher Neuzeit europäische und mittelmeerische Wissenswelten maßgeblich geprägt hat. Diese wenigen Anmerkungen zu transeuropäischen Bezügen müssen hier genügen.

Ein weiterer, eher forschungspraktischer Grund für die Beschränkung auf europäische Nachschlagewerke ist die fehlende sprachliche Zugänglichkeit der Lexika vieler anderer Weltgegenden. Schon die vorliegende auf Europa beschränkte Auswahl an Nachschlagewerken musste das Problem lösen, dass Forschungen v.a. zu osteuropäischen und skandinavischen Wörterbüchern und Lexika kaum auf Deutsch oder Englisch vorliegen; auch über die Romania wird verständlicherweise überwiegend auf Französisch, Italienisch, Spanisch, Portugiesisch und Katalanisch geschrieben. Da die Publikationssprache des vorliegenden Bandes aber Deutsch sein sollte, mussten AutorInnen gefunden werden, die die zu porträtierenden Werke und die darauf bezügliche Forschungsliteratur im Original lesen können. In zwei Fällen, beim Beitrag einer englischen Muttersprachlerin und beim englischsprachigen Beitrag eines schwedischen Muttersprachlers, konnten dank großzügiger Unterstützung des Verlags Übersetzungen ins Deutsche angefertigt werden. ${ }^{3}$ Im Ergebnis können die Leserinnen und Leser dieses Bandes durch die hervorragende inhaltliche wie sprachliche ,Übersetzungstätigkeit‘ der Autoren wie der professionellen Übersetzerin einen interdisziplinären Gegenstandsbereich kennenlernen, der in dieser Zusammenstellung bisher noch in keiner Sprache existiert.

Der europäische Rahmen des Bandes musste aber aus Umfangsgründen noch einmal eingeschränkt werden. Die Werkauswahl ist auf Deutsch lesende Adressaten ausgerichtet und hat daher ein Übergewicht bei den deutschsprachigen Nach-

3 Frau Christine Henschel sei an dieser Stelle ausdrücklich für die Übersetzungen gedankt. 
schlagewerken. Diese Setzung ist notwendig einseitig; sie wäre genauso einseitig, wenn die Publikationssprache Französisch und die Werkauswahl auf die Romania zentriert wäre, und sie wäre im Falle der Publikationssprache Englisch und einer damit notwendig einhergehenden anglo-amerikanisch perspektivierten Werkauswahl keineswegs weniger einseitig. Eine übergeordnete, ,neutrale' Perspektive auf den Gegenstand kann es nicht geben. Gegenüber deutschsprachigen Lesern scheint es legitim, den europäischen Horizont von den deutschsprachigen Ländern aus zu ziehen und vorrangig solche nicht-deutschsprachigen Werke auszuwählen, die von Sprechern des Deutschen am ehesten genutzt werden können, weil sie in einer schulnahen oder nachbarschaftlichen Fremdsprache geschrieben sind (Englisch, Französisch, Latein, Spanisch, Russisch, Niederländisch, Dänisch u.ä.). Die unterschiedliche Länge der Beiträge ist der Relevanzsetzung durch die Herausgeberin, teilweise aber auch der Forschungslage zum jeweiligen Werk geschuldet.

,Große und ,kleine' Lexika unterscheiden sich nicht nur nach Format und Bandzahl, d.h. nach ihrem Textumfang von einander. Hinter den umfangreichen Werken stehen in der Regel auch mehr Produktionsenergie, mehr Mittel und am Ende die größere Aufmerksamkeit der Umgebungsgesellschaft. Als hinreichend ,groß` und wichtig wurden daher solche Werke eingestuft, die eine größere Bekanntheit im eigenen Sprachgebiet und möglichst darüber hinaus erlangt haben; dies gilt z. B. in exemplarischer Weise für die große französische Enzyklopädie (Diderot/d'Alembert), für das Oxford English Dictionary und für das Grimmsche Wörterbuch. Diese großen Nachschlagewerke hatten und haben nicht selten kleinere Nachfolger oder ,seitliche Ableger', so dass sie auch in diese Richtung musterbildend wirken können. Jede Auswahl ist aber auch in dieser Beziehung eine Setzung.

Der Zeitraum, den die hier porträtierten Lexika abdecken, geht vom aktiven Umgang heutiger Adressaten mit den Nachschlagewerken aus. Nicht wenige der ,großen' weil einflussreichen Lexika liegen inzwischen digitalisiert vor und sind im Internet zugänglich. Aufgrund des geltenden Urheberrechts und mit Rücksicht auf die Vermarktung der je aktuellen gedruckten Lexika sind es nicht selten die älteren Werke oder Ausgaben, die auf digitalem Wege direkt auf den Schreibtischen Interessierter landen. Deren Nutzungsinteressen können streng genommen nur vermutet werden: Studierende und WissenschaftlerInnen aller Disziplinen, Lehrer, Journalistinnen und ,Kulturschaffende', Sachbuchautoren und Hobbyhistorikerinnen - sie alle können zu alten und jüngeren Lexika greifen, wenn sie Fragen wie z.B. folgende, zufällig gewählte haben:

- Wie und unter welchen Umständen hat sich die Textilfärbung (Krapp, Indigo, Berliner Blau) entwickelt? Welche der beteiligten Berufsgruppen gebrauchten dabei welche fachsprachlichen Mittel?

- Wie haben Seeleute vor der Erfindung genau gehender Uhren ihre Position auf See bestimmt, wie hießen die dazu benutzen Gerätschaften und wie sahen sie aus? 
- Was wusste das aufgeklärte Europa um 1830 über China und wie war dieses Wissen perspektiviert?

- Welche Kenntnisse hatte man um 1900 über Geburtshilfe in anderen Kulturkreisen?

- Mit welchen Wörtern sprachen Ärzte, Bader und Hebammen über tabuisierte Körperfunktionen und -zonen und wie hat sich dieser Wortschatz verändert?

- Welche Anglizismen (Germanismen, Gallizismen usw.) kannte das 19. Jahrhundert?

- Wann und wie entstand das heutige Konzept des Haustiers im Unterschied zum Nutztier?

- Wie haben sich die Charakterisierungen berühmter Personen (durch äußerliche Merkmale, Charaktereigenschaften, gesellschaftlichen Funktionen, Leistungen, private Lebensumstände) verändert?

- Welche Bedeutung(en) hatte(n) das Wort $X$ zu beliebigen Zeitpunkten?

- usw., usw.

Nutzer werden meist mit den Lexika zu einem gegenwärtigen Sprachstand und zum aktuellen Wissensstand beginnen; diese sind in der zu treffenden Auswahl somit zentral. Aber auch die der Gegenwart näher liegenden historischen Stadien von Sprach- und Weltwissen sind für eine hohe Zahl von Nutzungsanlässen von großem Interesse. Geistes- und kulturwissenschaftliche Fragen und Begriffe sind ohne eine historische Tiefe kaum angemessen verstehbar, und auch für viele naturwissenschaftliche und technische Themen ist das Nachvollziehen der Wissensentstehung und -entwicklung gerade für fachliche Laien wichtig. Die aktuellen Nachschlagewerke des 21. Jahrhunderts können aber kaum alle möglicherweise interessanten Entwicklungsstufen unseres Wissens mit enthalten. Dieser Band versucht daher, eine prägnante Auswahl der wichtigsten und ,großen ' Nachschlagewerke Europas von der Epoche der Aufklärung bis zur Gegenwart zu bieten; aus guten Gründen werden aber zwei frühere Wörterbücher aus der Romania an den Anfang gestellt, weil sie die Entwicklung der Nachaufklärungszeit maßgeblich beeinflusst haben, das Wörterbuch der florentinischen Akademie und das der königlich-spanischen Akademie. Dem Fischaugen-Prinzip folgend sind die Lexika dieses Bands ungleich auf die Epochen seit der Voraufklärung verteilt. Je näher man der Gegenwart kommt (ausgehend von der Epoche der europäischen Aufklärung, über das 19. Jahrhundert als Epoche des Bürgertums und der technologischen Expansion, zum 20. und zum Beginn des 21. Jahrhunderts als Gegenwart), desto ,dichter' wird das Feld der als relevant ausgewählten Werke.

Es sind vorrangig solche historischen Lexika Europas berücksichtigt, zu denen potenzielle LeserInnen heute (noch) Hintergrundinformationen, kontextualisierende Interpretationshilfen und - ggf. auch - ein Stück ,spannender Wissensgeschichte' nachlesen möchten. Dieser Wunsch wird hier hoffnungsvoll unterstellt, denn üblicherweise dienen Lexika der raschen Information, dem punktuellen $\mathrm{Zu}$ - 
griff und nicht einer ausgedehnteren Lektüre. Vor- oder Nachworte und sonstige Hilfe-Texte von Nachschlagewerken (sog. Umtexte) werden bekanntlich nicht gelesen. Gegenüber den eigenen Zeitgenossen sind Lexika auch so angelegt, dass sie ,gefahrlos' ohne Kenntnis der Umtexte rezipiert werden können. Doch mit wachsendem zeitlichen Abstand zwischen Lexikon und Nutzungssituation wächst die Unsicherheit im Verstehen der Informationen; schlimmstenfalls kommt es zu folgenschweren Irrtümern, wenn z.B. Studierende aus der Tatsache, dass das Wort Kultur im Grimmschen Wörterbuch nicht als Stichwort angesetzt ist, folgern, dass das Wort $1854 \mathrm{im}$ Deutschen noch nicht bekannt war, oder wenn dem Autor eines Wörterbuchs mit dem Titel Wörterbuch zur Erklärung und Verdeutschung der unserer Sprache aufgedrungenen fremden Ausdrücke eine im heutigen Verständnis ,rechtsgerichtete' Gesinnung zugeschrieben wird. Falsche Erwartungen und fehlgehende Schlüsse können nur durch Hintergrundinformationen zu den betreffenden Nachschlagewerken vermieden werden. Und erst wer Informationen zum zeitgeschichtlichen Kontext, zur Produktionsweise, zu den Autoren und zur Sprach-, Kultur- und Wissenschaftsgeschichte ganz allgemein zur Kenntnis genommen hat, kann die Vermitteltheit und Konstruktivität des niedergelegten Sprach- oder Sachwissens begreifen. Nachschlagewerke gelten oft als ultimativ objektive und ,neutrale' Quellen, aber sie unterscheiden sich in ihrer Standpunktgebundenheit nicht von anderen Texten, seien es literarische oder sachbezogene: Sie sind auf spezifische Weise eingebunden in Diskurse und spielen in ihnen oft sogar herausragende Rollen, gerade weil sie für unparteiisch gehalten werden.

Selbstverständlich hat sich auch der Forschungsstand auf die Werkauswahl ausgewirkt. Im Falle der Sprachlexikografie darf er als deutlich umfangreicher bezeichnet werden; die Philologien nicht nur zu den europäischen Sprachen haben ihrem Arbeitsinstrument Wörterbuch immer schon große Aufmerksamkeit gewidmet; die umfangreiche lexikografietheoretische Forschung in den letzten drei bis vier Jahrzehnten tat ihr Übriges. Im Falle der Sachlexikografie (oder Enzyklopädik) scheint das multidisziplinäre Interesse an der Gattung nicht zu einem dazu parallelen konsistenten Ensemble analytischer und klassifikatorischer Kriterien geführt zu haben. Selbst dokumentierend-beschreibende Überblicks- wie Einzeldarstellungen der enzyklopädischen Landschaft eines Landes oder einer Kultur sind nicht durchweg vorhanden oder wenn, dann in der eigenen Landessprache. ${ }^{4}$

\footnotetext{
4 Z.B. existiert zu den drei großen schwedischen Enzyklopädien, deren 20, 30 und mehr Bände zwischen 1876 und 1996 erschienen sind (Nordisc familjebok, Svensk uppslagsbok und Nationalencyklopedin), nur ein neueres populärwissenschaftliches Buch in schwedischer Sprache. Ich danke Sven-Göran Malmgren, Göteborg, für diesbezügliche Recherche und Mitteilung.
} 
Die Auswahlkriterien der in diesem Band behandelten Werke in der Zusammenfassung:

K1 Raum: Europa, von Deutschland aus gesehen und fokussiert

K2 Zeit: Aufklärung mit wachsendem Gewicht zur Gegenwart hin

K3 Typen: umfängliche einsprachige Sach- und Sprachnachschlagewerke

K4 Relevanz: Rezeption und ,Strahlkraft ${ }^{\prime}$ über die jeweilige Sprachlandschaft hinaus

\section{Zu Auswahl und Anordnung der Werkartikel im Einzelnen}

Die Anordnung folgt historisch-systematischen Aspekten, ist also nicht streng chronologisch. Vier Epochen lassen sich unterscheiden, von denen die früheste Traditionen aus dem Barock, v.a. aber aus der Renaissance und dem Mittelalter aufgreift, ohne dass auf diese Fundamente hier näher eingegangen werden kann (Näheres in Eybl et al. 1995).

\section{Frühe Ordnungen}

Vocabolario degli Accademici de la Crusca

Das Crusca-Wörterbuch stammt seiner Konzeption nach noch aus dem letzten Jahrzehnt des 16. Jahrhunderts und war Vorbild und z. T. unmittelbare Vorlage für die Wörterbücher anderer europäischer Akademien, explizit für das spanische. Noch im 19. Jahrhundert hatte es einen legendären Ruf, so dass Jacob Grimm sich darauf berufen konnte. Ziel des von der florentinischen Akademie getragenen, für seine Zeit äußerst umfangreichen Werks waren Bewahrung und Förderung der Sprachkultur; Autoren wie Dante, Petrarca und Boccaccio dienten als Vorbilder. Die schlechten Elemente der Sprache sollten wie Kleie (crusca) von den guten getrennt und ,ausgesiebt' werden, ein Ziel, mit dem sich viele andere Länder und Regionen Europas bis ins späte 19. Jahrhundert hinein identifizieren konnten. Auch in methodischer Hinsicht setzte das Werk Maßstäbe und blieb damit das europäische ,Leitwörterbuch`.

\section{Der Diccionario de la lengua española der Real Academia Española}

Das Wörterbuch steht beispielhaft für andere Akademie-Wörterbücher v.a. aus der Romania, die im frühen 18. Jahrhundert mit dem Ziel des funktionalen Ausbaus der eigenen Kultursprache und der Steigerung ihrer Ausdruckskraft initiiert wurden und die einander in einem, europäischen Sprachenwettstreit‘ wahrnahmen. Das spanische Akademiewörterbuch weist eine einzigartige, bis heute durchgängige Auflagengeschichte auf, in deren Verlauf nicht nur methodische Verbesserungen stattfanden, sondern auch der Wortschatz der spanischen Varietäten in 
Amerika und auf den Philippinen Berücksichtigung fanden. Das DRAE ist eine in Sprachfragen Orientierung gebende Institution der gesamten spanischsprachigen Welt.

Für die europäischen Enzyklopädien vom Mittelalter bis zum Beginn des 18. Jahrhunderts gilt cum grano salis, dass sie auf Lateinisch für gelehrte Kreise verfasst, in theologisch-kirchliche Argumentation eingebunden und in fachlichsachlicher Hinsicht selten universal, sondern eher breit diversifiziert waren. Säkularisierung, Verwissenschaftlichung und eine gewisse Technologisierung der europäischen Kulturen trugen in der Folge (etwa ab Mitte des 18. Jahrhunderts) wesentlich dazu bei, die alphabetische Anordnung der Stichwörter an die Stelle der theologischen Begriffssysteme zu setzen.

Impulse der Aufklärungszeit.

Systeme der Vernunft und praktischer Nutzen

Encyclopadia Britannica

Diese - weil englischsprachig - weltweit berühmteste Enzyklopädie entstand in der zweiten Hälfte des 18. Jahrhunderts, im Kontext der schottischen Aufklärung, in konzeptioneller Auseinandersetzung mit dem wenig älteren, berühmten französischen Vorbild. Doch anders als letzteres gelangen der Britannica eine bis heute ununterbrochene Auflagengeschichte und damit die notwendigen Anpassungen an veränderte Zeiten, das Internet-Zeitalter eingeschlossen. Ein wesentliches Kennzeichen der Britannica war und ist, dass sie berühmte Wissenschaftler und Experten auf ihrem Gebiet als Autoren hinzuziehen konnte, die ihre Beiträge auch namentlich kennzeichneten. Der Zersplitterung des Wissens durch die alphabetische Anordnung begegnete die Britannica schon früh mit durchdachten Verweissystemen und komplementären Registern. So war sie für hypertextuelle Strukturen der Online-Welt gut gerüstet. In ökonomischer Hinsicht hat die Britannica viele Krisen durchlebt und ist heute eine Marke, unter der sich viele verschiedene Produkte des Bildungsmarkts versammeln.

\section{Krünitz: Oeconomische Encyclopädie}

Krünitz steht in diesem Band exemplarisch für deutschsprachige Universalenzyklopädien der Aufklärungsepoche; die Wahl hätte möglicherweise auch auf das mittlerweile recht gut erforschte Universal-Lexicon von Zedler (Schneider 2004, Dorn 2008) fallen können, doch wird Zedler, dessen Unternehmen zur selben Zeit endete, in der die große französische Encyclopédie begann, von manchen nicht mehr der Aufklärungszeit oder zumindest der Voraufklärung zugerechnet. Krünitz ${ }^{5}$ ist wie Zedler ${ }^{6}$ im Internet zugänglich und durch die damit verbundene

\footnotetext{
5 Außer Reinstein zu Krünitz in diesem Band siehe auch Seifert 2008.

6 http://www.zedler-lexikon.de
} 
(unterschiedliche) Systematisierung weit besser benutzbar als die gedruckten vielbändigen Originale. In die Reihe deutschsprachiger Enzyklopädien des 18. Jahrhunderts gehört knapp auch noch Ersch-Gruber (ab 1818; 1971 Nachdruck der Ausg. von 1840). ${ }^{7}$ Die allen genannten gemeinsame Intention stammt aus der Aufklärung, ohne dass die große französische Enzyklopädie in jedem Falle Vorbild gewesen wäre. Ihr Anspruch auf Vollständigkeit und die fraglos unterstellte Produktionsweise war auf absolutistische Förderung per Monopol und Alimentierung durch Fürsten oder Verleger angewiesen, doch konnte die Produktion immer neuer Bände, v.a. bei Krünitz mit der Ausdifferenzierung des Wissens in der nachabsolutistischen und schließlich bürgerlichen Gesellschaft nicht mithalten, so dass diese ausufernden Wege auch Zeugnisse großartigen Scheiterns geworden sind.

\section{Diderot/d'Alembert: L'Encyclopédie ou dictionnaire raisonné des sciences, des arts et des métiers}

Diese wohl berühmteste Enzyklopädie der Geschichte ist wie kaum ein anderes Werk mit dem Epochenbegriff der Aufklärung assoziiert und markiert mit seinem Erscheinen ab 1751 den Beginn des neuzeitlichen, wenn nicht gar modernen Wissens. Sie gilt als ,das' Medium des aufgeklärten Menschenbilds und muss v.a. kulturgeschichtlich, d.h. in einem weiten Kontext von Politik und Gesellschaft, von Philosophie und Ökonomie gesehen werden. Ihre Strahlkraft reichte weit über nationale und europäische Grenzen hinaus. An ihr ließ und lässt sich studieren, wie und warum ein Nachschlagewerk kein bloßer Informationsspeicher, sondern ein Instrument der Emanzipation, gar des Widerstands sein kann.

Dansk Ordbog udgiven under Videnskabernes Selskabs Bestyrelse

Das Wörterbuch der dänischen Akademie der Wissenschaften, dessen Vorarbeiten ins Jahr 1693 zurückreichen, erschien in acht Bänden von 1793 bis 1905 und schließt historisch an die frühen romanischen Vorbilder Italiens und Spaniens an. Damit wurzelt es einerseits im aufgeklärten Absolutismus und seinen volksaufklärerischen Absichten, sollte aber andererseits den dokumentarischen Interessen der Sprachforscher im 19. Jahrhundert, d.h. der nachfolgenden Epoche genügen - ein Wörterbuch, das über 210 Jahre hin im Brennpunkt kontroverser sprachpolitischer und wissenschaftlicher Interessen der dänischen Sprachnation stand.

\section{Johnson: Dictionary of the English Language}

Samuel Johnsons enorm erfolgreiches Werk mit bearbeiteten Neuauflagen bis in die 1950er Jahre hinein trug maßgeblich zur Standardisierung der englischen Spra-

7 Druckausgabe Ersch-Gruber 1840/1971; zur Digitalisierung der Allgemeinen Encyclopädie der Wissenschaften und Künste, von Johann Samuel Ersch und Johann Gottfried Gruber in der Auflage von 1818 siehe http://resolver.sub.uni-goettingen.de/purl?PPN362308799, zuletzt eingesehen am 27.9.2010. 
che bei und besticht noch heute durch seine systematische Methodik, die die Bedeutungserläuterung an den Anfang eines jeden Wortartikels stellte. Johnson schloss sich dabei explizit an den europäischen Sprachenwettstreit an - wo Italiener und Franzosen nationalsprachliche Wörterbücher besäßen, dürfe das eigene Land nicht länger hintanstehen. Johnsons Wörterbuch diente in vielen Ländern Europas als Referenzwerk und methodisches Vorbild.

Adelung: Grammatisch-kritisches Wörterbuch der Hochdeutschen Mundart Adelungs Wörterbuch war dasjenige Werk, von dem Jacob und Wilhelm Grimm ihr so ganz anders angelegtes Wörterbuch fünfzig Jahre später kritisch abgrenzten. Für Jacob Grimm war Adelung ein trockener Zergliederer der lebendigen Sprache, für Goethe und Schiller ein viel genutztes, Orakel', denn - so sieht man es heute der Adelung repräsentierte den überregionalen (relativen) Standard des Deutschen, der um 1800 erreicht war. Dass der Adelung das in der Germanistik des 20. und 21. Jahrhunderts am intensivsten erforschte Werk ist, liegt an seiner für damalige Verhältnisse innovativen Methodik, seiner Klarheit und Rationalität, die auch heute noch nicht jedes Wörterbuch erreicht. Ähnlich wie Johnson hat Adelung vielen anderen nationalsprachlichen Wörterbüchern in Europa als Vorbild gedient.

\section{Campe: Wörterbuch der deutschen Sprache}

Joachim Heinrich Campe war Pädagoge und Aufklärer auch in seinen politischen Einstellungen. Bekannt für seine Fremdwortfeindlichkeit wird er gelegentlich als ,konservativ' missverstanden, doch es ging ihm um die Popularisierung aufklärerischer Bildungsmedien und darum, Bevölkerungskreisen ohne höhere Schulbildung die Teilhabe an Bildung und letztlich am öffentlichen Diskurs zu ermöglichen. Auch wenn er sich lexikografisch vehement von Adelung abgrenzte, wurde sein Wörterbuch zur idealen Ergänzung des Adelungschen.

Orientierungen des 19. Jahrhunderts: Geschichte und Nation

\section{Brockhaus Konversationslexikon}

Der Brockhaus ist im deutschsprachigen Raum der Prototyp des Konversationslexikons bzw. der Enzyklopädie geblieben. Seine lange, mit der bürgerlichen Gesellschaft eng verknüpfte und enorm erfolgreiche Geschichte ist im Jahre 2009 beendet worden - das Internet und die strikte Ökonomisierung der Medienwelt haben dazu geführt, dass der Verlag Bibliographisches Institut (BIFAB) die Marke Brockhaus an einen anderen Medienverlag, einen ,Mitbewerber', verkauft hat. Es bleibt abzuwarten, ob letzterer den Brockhaus mit seinen eigenen Produkten verschmilzt oder - unwahrscheinlicher - ihn als eigenständiges Werk weiterführen wird. 
Deutsches Wörterbuch von Jacob Grimm und Wilhelm Grimm

Dieses vielleicht berühmteste Wörterbuch zur deutschen Sprache der auch in bildungsferneren Kreisen bekannten ,Märchen'-Brüder Jacob und Wilhelm Grimm ist zugleich das umfangreichste Wörterbuch des Deutschen überhaupt, obwohl große Teile des Lehn- und Fremdwortschatzes ausgeschlossen wurden. Die Initiative ging von einem Verleger aus, der dabei auch den überraschend großen Erfolg des Brockhaus im Auge hatte. Wie kaum ein anderes Werk ist der Grimm mit der europäischen Geschichte des 19. Jahrhunderts verbunden, indem es auch anderen Nationen zeigte, wie ein Wörterbuch zur Unterstützung des Nationalbewusstseins beschaffen sein muss. Es hat zahlreiche berühmte ,Nachahmer' gefunden.

\section{Oxford English Dictionary}

Zeitlich etwa parallel zum Grimmschen Wörterbuch entstanden, versuchte das $O E D$, die historische Betrachtung des Wortschatzes mit jener nüchternen Dokumentation aller Wörter und Wortverwendungen zu verbinden, die dem Grimm in den ersten Jahrzehnten fehlte. Diese Kombination sowie die sukzessive Öffnung für und die unparteiische Dokumentation der Wortschätze anderer englischsprachiger Länder hat den Grundstein für die heutige weltweite Geltung des Wörterbuchs gelegt, die durch frühes und innovatives Aufgreifen der neuen Technologien noch gestärkt wird. Das OED ist eines der wenigen Nachschlagewerke, dessen Entstehungsgeschichte zu Romanen inspiriert hat.

\section{Sanders: Wörterbuch der deutschen Sprache}

Dieses in Konkurrenz zum und in kritischer Auseinandersetzung mit dem Werk der Brüder Grimm entstandene Wörterbuch zeigt, dass lexikografische Konzeptionen, auch wenn sie zu monumentalen Werken führen, grundsätzlich nicht alternativlos sind. Welche Art von Wörterbuch die deutsche Nation noch vor und während ihrer staatlichen Einigung in der zweiten Hälfte des 19. Jahrhunderts haben sollte, war eine Frage, die der jüdische Deutsche Daniel Sanders anders als Jacob und Wilhelm Grimm unter bewusstem Rückgriff auf aufklärerische Prinzipien beantwortete. Sein fast vergessenes Werk kann heutige Fragen zur Sprach- und Kulturgeschichte des 19. Jahrhunderts jedoch vielfach besser beantworten als der Grimm.

\section{Woordenboek van de Nederlandsche Taal}

Das WNT ist mit seinen 43 Bänden eines der umfangreichsten Sprachnachschlagewerke Europas überhaupt. Es wurde in ganz ähnlichen kulturellen Umständen Mitte des 19. Jahrhunderts begründet, fort- und im 20. Jahrhundert zuende geführt wie das Wörterbuch der Brüder Grimm. Es spielt und spielte eine vielleicht sogar noch bedeutendere sprachenpolitische Rolle, insofern es die staatliche Grenzen übergreifende Einheit der niederländisch-flämischen Sprache dokumentiert (Niederländisch ist Nationalsprache in den Niederlanden und in Belgien). 


\section{Thesaurus linguae Latinae}

Ziel dieses Wörterbuchs ist die nahezu vollständige Dokumentation und Beschreibung des antiken lateinischen Wortschatzes von den Anfängen bis 600 n. Chr. Der ThlL stellt damit das sprachliche Fundament des gebildeten, sich des Lateins bedienenden Europas dar und er ist auch arbeitsorganisatorisch - an seiner Erarbeitung sind seit Ende des 19. Jahrhunderts bis heute mehrere nationale Akademien auf drei Kontinenten beteiligt - ein gesamteuropäisches Projekt. Dennoch ist das vollständig auf Latein verfasste Werk kaum bekannt und in seinem Potenzial als semantisch-kategorialem Fundament fast aller europäischen Volks- bzw. Nationalsprachen wohl noch nicht erkannt. Dass Lateinkenntnisse in der höheren Allgemeinbildung einmal so marginalisiert werden würden, wie es heute der Fall ist, war den Initiatoren am Ende des 19. Jahrhunderts wohl nicht vorstellbar.

Das schwedische Akademiewörterbuch und das Wörterbuch der dänischen Sprache Das Wörterbuch der Schwedischen Akademie der Wissenschaften geht zwar auf Impulse der Aufklärungsepoche und auf den Wunsch der Kodifikation der schwedischen Standardsprache im 18. Jahrhunderts zurück, wurde jedoch aufgrund methodischer Probleme erst Ende des 19. Jahrhunderts unter den Vorzeichen der historisch-entwicklungsbezogenen Sprachforschung wirklich begonnen. Es soll bis 2020 abgeschlossen sein und ist mit seinen dann knapp 40 Bänden und einer mehr als einhundert Jahre andauernden Entstehungszeit das unbestreitbar größte schwedische Wörterbuch. Das Wörterbuch der dänischen Sprache wird im Beitrag mitbehandelt, da es sich in der Konzeption eng an das schwedische Vorbild anlehnte und ebenfalls auf die historisch-entwicklungsbezogene Betrachtung des nationalsprachlichen dänischen Wortschatzes festgelegt ist. Seine 33 Bände wurden 1956 nach nur 38 Jahren fertiggestellt. Die Verbindungen zwischen den beiden skandinavischen Wörterbüchern ist gewissermaßen enger als diejenige der beiden dänischen (d.h. des historisch-entwicklungsbezogenen und des oben behandelten dänischen Akademiewörterbuchs der Aufklärungsepoche) untereinander. Der Vergleich ähnlich umfangreicher Wörterbücher zweier eng verwandter Sprachen eignet sich gut zum Sprachvergleich; beide sind inzwischen im Internet zugänglich.

\section{Pauls Deutsches Wörterbuch}

Der Sprachwissenschaftler und Philologe Hermann Paul war ein Zeitgenosse Ferdinand de Saussures; beide markieren für die Germanistik den Beginn der modernen wissenschaftlichen Sprachwissenschaft. Pauls Deutsches Wörterbuch, das ,nur einen Band umfasst, entstand am Ende des 20. Jahrhunderts aus anderen Motiven heraus als die übrigen, deutlich voluminöseren Nachschlagewerke dieser Epoche: Es ging Paul hier vor allem um die lexikografisch-praktische Umsetzung seines ,streng' wissenschaftlichen Programms. Das Wörterbuch ist konsequent bedeutungshistorisch, nicht etymologisch ausgerichtet und steht für die fruchtbaren Wechselwirkungen zwischen Sprachwissenschaft einerseits und Sprachlexikografie 
andererseits. Das Werk hat sich das gesamte 20. Jahrhundert hindurch und bis heute mit seinen zehn Auflagen, sicherlich auch wegen seiner Handlichkeit, beträchtlicher Beliebtheit, insbesondere beim deutschen Bildungsbürgertum, erfreut.

\section{Roget's Thesaurus}

Der englische Arzt Peter Mark Roget versuchte im 19. Jahrhundert, nach dem Vorbild der heute noch genutzten zoologischen Taxonomie des Schweden von Linné den Wortschatz in exakt 1000 begriffliche Klassen und paarweise angeordnete Subklassen einzuteilen. Seine Synonymik wurde ein Riesenerfolg und fand seinerseits Nachahmer in anderen europäischen Sprachen. Seine Aufnahme wie auch die der unten charakterisierten Synonymik von Dornseiff in diesen Band wurde oben bereits begründet. In einer Zeit, als sich die alphabetische Anordnungsweise vollständig durchgesetzt zu haben schien, der Computer aber noch nicht erfunden war, stellten diese Werke wichtige Versuche zur Wiederherstellung der Sinnzusammenhänge im Wortschatz dar.

\section{Hrincenkos Wörterbuch der ukrainischen Sprache und Akademisches Wörterbuch der Ukrainischen Sprache}

Ersteres entstand um die Wende vom 19. zum 20. Jahrhundert, letzteres in der zweiten Hälfte des 20. Jahrhunderts. Beide zeigen, welche sprachpolitische Bedeutung einem Sprachwörterbuch zugemessen werden kann, wenn weder die betreffende Sprache noch die nationalkulturelle Sprechergemeinschaft in ihrer Autonomie politische Anerkennung finden. Das Ukrainische wurde sowohl im zaristischen Russland als auch in der Sowjetunion unter existenzbedrohenden Druck gesetzt. So kann ein Wörterbuch, das einerseits zur lexikalischen, grammatikalischen und orthografischen Standardisierung einer aus dem Bildungssystem verbannten Sprache beitragen will, andererseits aber auch die dialektalen Varietäten dokumentieren will und dies alles nur unter Rückgriff auf die politisch dominierende Sprache Russisch realisieren kann, zum Garanten einer bedrohten nationalen Identität werden. Beflügelt durch die europäischen Nationalbewegungen begann ein beachtlich großer Kreis ukrainischer Intellektueller schon Mitte des 19. Jahrhunderts mit lexikografisch-konzeptionellen Überlegungen und mit dem Sammeln von Belegmaterial. Ganz ähnliche lexikografische Situationen wie für die des Ukrainischen hätte man auch für die meisten anderen Sprachen der Länder der ehemaligen Sowjetunion skizzieren können, doch auch in westlicheren Gegenden Europas gab und gibt es politisch unterlegene Sprachen, für deren Stützung ein aus eigenen Quellen erarbeitetes, d.h. nicht durch bloßes Umschreiben und Umordnen entstandenes Wörterbuch zu einem zentralen politischen Dokument wie Instrument werden kann. 
Trésor de la langue française

Das sechzehnbändige historisch-dokumentierende und gegenwartsorientierte Wörterbuch entstammte ideell zwar dem 19. Jahrhundert, doch stellt es aktuell nicht nur eines der wichtigsten Referenzwerke des französischen Wortschatzes einschließlich der Frankophonie außerhalb des Mutterlands dar, sondern fand mit seiner Fertigstellung in den 1990er Jahren auch unmittelbaren Anschluss an das elektronische Zeitalter. Der Beitrag behandelt ausführlich den TLFi (Trésor de la langue française informatisé) mit und zeigt, wie computer- bzw. korpuslinguistische Forschung, moderne Sprachwissenschaft (hier: der Strukturalismus) im Verein mit guter finanzieller Ausstattung zu lexikografischen Innovationen führen. In dieser besonderen Verbindung von älterem Wörterbuchmaterial, neuen Technologien und Ausweitung des Beschreibungsgegenstands auf mehrere Varietäten und die Gegenwart (ähnlich dem $O E D$ ) liegt die Strahlkraft des Unternehmens TLF weit über Frankreich hinaus.

Das 20. und 21. Jahrhundert: neue Systementwürfe, Perspektivierung und Fragmentierung des Wissens

Enciclopedia Italiana di scienze, lettere ed arti (Enciclopedia Treccani), 1929-1937

Die Treccani ist in Italien, was der Brockhaus in Deutschland ist. Allerdings geht die italienische Enzyklopädie auf eine neue und eigenständige Konzeption vom Beginn des 20. Jahrhunderts zurück, die die nationale wie gesamteuropäische Bedeutung Italiens, auch in Konkurrenz zu Frankreich, dokumentieren sollte. Ein eigens gegründetes Institut sorgte für die Kooperation tausender von Autoren. Dass der Beginn der Arbeit in die Zeit des faschistischen Regimes unter Mussolini fiel und dass letzterer selbst an der Enzyklopädie als an einem Prestigeobjekt mitarbeitete, macht die Geschichte besonders interessant. Enzyklopädien überdauern so manches Regime und behaupten oft gar ihre ursprünglichen ,vernünftigen' Konzeptionen. Dennoch müssen die jeweiligen Bände mit entsprechendem Wissen rezipiert werden. Die Treccani ist heute ein Internet-Portal mit vielfältigem und aktuellem Produktangebot und sie verbindet inzwischen Sprach- und Sachlexikografie in ein und demselben Alphabet. Die methodischen Gründe dafür sind nicht von der Hand zu weisen, doch zeigt sich: Gewinner ist die Enzyklopädie, in der das Sprachwörterbuch bzw. Sprachwissen verschwindet. Ob diese Eigenschaft Nachahmung in anderen Sprachkulturen findet, bleibt abzuwarten.

Enzyklopädie der Ukrainekunde, 1949-1995

Ähnlich wie die o.g. Wörterbücher der ukrainischen Sprache wurde nach dem 2. Weltkrieg aus einem Kreis über die Welt verstreut lebender Exil-Ukrainer eine Enzyklopädie als wichtiges nationales Projekt geschaffen, das eine Reaktion auf die politische Lage der Ukraine unter der russischen, österreichischen und später unter 
der polnischen und sowjetischen Herrschaft darstellte. ${ }^{8}$ Die Enzyklopädie sammelte und systematisierte nicht nur die bedrohten Elemente der ukrainischen Kultur, einschließlich Geschichte, Sprache, Literatur, Kunst, regionaler Kulturen und Dialekte, Kirche, Forschung, Recht und vielem mehr, sondern dokumentierte und betonte darin auch die Verbindungen der Ukraine mit anderen, so auch gesamteuropäischen Traditionen wie der Antike. Das Werk steht exemplarisch für eine Funktion, die auch andere Enzyklopädien mehr oder weniger deutlich aufweisen, nämlich die Funktion der Sicherung und der Sichtbarmachung einer $\mathrm{Na}$ tion und ihrer Kultur, wo andere Domänen dafür verschlossen sind. Dies kann, muss aber offensichtlich nicht in eine künstliche Konstruktion von Besonderheiten und in scharfe Abgrenzung von den dominanten Staaten, Kulturen und Sprachen münden.

\section{Klappenbach/Steinitz: Wörterbuch der deutschen Gegenwartsprache}

Das in der Deutschen Demokratischen Republik entstandene Werk zeichnet sich erstens durch Bindung an die strukturalistische Sprachwissenschaft vornehmlich russisch-tschechischer Prägung aus und wurde damit zum Meilenstein moderner lexikografischer Methodik. Zweitens lieferte es Vorbild und sogar Grundstock für das erste umfangreichere Nachkriegswörterbuch des Duden-Verlags in Westdeutschland. Es ist drittens ein Wörterbuch, das die Frage der Ideologie- bzw. Weltbildgebundenheit ,objektiver ' Wörterbuchinformationen offensiv und damit exemplarisch behandelt. Dass es dadurch keineswegs ganz überholt ist, zeigt drittens seine Einbindung in ein modernes digitales Informationssystem, vergleichbar dem OED und dem TLFi.

Dornseiff: Der deutsche Wortschatz nach Sachgruppen

Dornseiff, ein Gräzist, versuchte im frühen 20. Jahrhundert für das Deutsche etwas Ähnliches wie Roget für das Englische des 19. Jahrhunderts. Als stilistisches Hilfsmittel hatte ,der Dornseiff großen Erfolg, bis seine Materialgrundlage veraltet war. Erst vor wenigen Jahren konnte mithilfe computerlinguistischer und computerlexikografischer Möglichkeiten eine interessante Neuinterpretation der Wissensordnung entwickelt werden. Wo heutzutage sich Informationswissenschaft und Künstliche Intelligenz um die Erstellung semantisch strukturierter Thesauri und sog. ontologies (,Semantic Web') bemühen, könnte die Kenntnis dieses Werks, das etliche Aspekte und Probleme der gemeinsamen Aufgabe schon Jahrzehnte zuvor reflektiert und z.T. beantwortet hat, nützlich sein.

8 Der ursprünglich geplante Beitrag zur Großen Sowjetischen Enzyklopädie, die zwischen 1926 und 1978 drei Auflagen erlebte, ließ sich aufgrund der unzureichenden Forschungslage leider nicht realisieren. 
Der Duden - eine Wörterbuchfamilie; Wahrig, Deutsches Wörterbuch Das größte und aktuelle Sprachwörterbuch der deutschen Sprache ist der Markenbezeichnung Duden verknüpft, unter deren Dach sich allerdings etliche andere Sprachbildungsmedien versammeln. Der bekannteste ist der sogenannte Rechtschreibduden, doch kann dieser kleine Einbänder die Ansprüche an Dokumentation der deutschen Gegenwartssprache nicht erfüllen. Im Hinblick auf Ausführlichkeit und Nachweis durch Belegmaterial gebührt dem wenig bekannten, zehnbändigen Großen Wörterbuch der deutschen Sprache von 1999 der Vorrang; im Hinblick auf Aktualität der Informationen zu Bedeutung und Gebrauch der Wörter wird das Duden Universalwörterbuch porträtiert. Da sich ein eigener Beitrag für die Wörterbuchfamilie des zum Bertelsmann-Konzern gehörenden Wahrig nicht verwirklichen ließ und auch, weil die Geschichte beider Familien in der Bundesrepublik der Nachkriegszeit zusammen gesehen werden sollte, behandelt der Beitrag auch den Wahrig. Die Konzeptionen beider ist in Auseinandersetzung mit neuen sprachwissenschaftlichen Paradigmen entstanden. Neben strukturellen Orientierungen finden sich insbesondere sprachpragmatische und korpuslinguistische Ansätze der Bedeutungsbeschreibung.

\section{Wikipedia}

Der Band schließt mit dem heutzutage wohl bekanntesten und am häufigsten genutzten Sachnachschlagewerk des digitalen Zeitalters, das hier kaum näher vorgestellt werden muss. Der Beitrag stellt aber nicht nur das mehr oder weniger Bekannte zu dieser internationalen, Werkfamilie' zusammen, sondern bringt auch Informationen zu weniger bekannten Hintergründen und Prinzipien der der Wikipedia zugrundeliegenden Arbeitsweisen, so dass das Verhältnis der Wikipedia, die ja aus etlichen nationalsprachlich spezifischen Wikipedias besteht, zur europäischen enzyklopädischen Tradition bestimmt werden kann.

\section{Zur Anlage der Werkartikel}

Jeder Artikel bezieht sich zentral auf ein bestimmtes Werk und seine Geschichte von der ersten Auflage an. Sinnvollerweise wird die Betrachtung gegebenenfalls auf ,Werkfamilien', bestehend aus großen und kleineren Nachschlagewerken desselben Typs ausgedehnt. Folgende Aspekte werden - oft auch in ihrer Reihenfolge als Textabschnitte jedes Beitrags - berücksichtigt. Abweichende Gliederungen spiegeln Besonderheiten der betreffenden Werke, z. T. auch die Forschungslage wieder.

\subsection{Werkbiografie}

Hier wird eine abrissartige Geschichte der Auflagen bis hin zu Digitalisierungen, der Konzeptions- und Bearbeitungsphasen, der prägenden Persönlichkeiten und 
eventuell sonstiger für die Entwicklung des Werks wichtiger Ereignisse skizziert. In den nicht seltenen Fällen einer, Werkfamilie‘ wird hier auch ein Überblick über verwandte und v.a. abgeleitete Kurz- oder andere Versionen des Hauptwerks gegeben.

\subsection{Konzeption/Programmatik}

Hier werden die lexikografischen bzw. enzyklopädischen Ideen der Gründer im kulturellen und historischen Kontext vorgestellt. Es wird deutlich, wo ein Werk auf ein anderes Bezug nimmt, sei es zustimmend nachahmend oder kritisch abgrenzend. Dies ist insofern wichtig, als nicht selten die spätere Realisierung von den ursprünglichen Plänen abwich. Nicht immer ist das Verhältnis von Plan und Umsetzung aber hinreichend erforscht. Auch ökonomische Aspekte (wie Auflagen, Verlagspolitik) und Verflechtung mit anderen Diskursen der Zeit werden hier so weit möglich thematisiert.

\subsection{Tatsächlicher Informationsgehalt}

Hier geht es um Inhaltstypen und Struktur der Wort- oder Sachartikel. Es werden die wesentlichen, nachrangigen und ggf. die fehlenden Informationsarten (im Wörterbuch) bzw. Informationselemente (in der Enzyklopädie) erläutert. Ziel ist die Unterstützung heutiger LeserInnen bei der Informationsentnahme aus den teilweise schon nicht mehr ganz leicht zu rezipierenden Werken. Die Digitalisierung historischer Lexika kann, entsprechenden Annotationsaufwand vorausgesetzt, die methodisch unzureichende Verweisstruktur kompensieren und den $\mathrm{Zu}$ griff auf ähnliche, aber unsystematisch angeordnete Informationen oft überhaupt erst ermöglichen, so dass ein Digitalisat deutlich mehr Informationspotenzial birgt als die gedruckte Version (vgl. Seifert 2008: 174). Die Entwicklung von OnlineAngeboten parallel zu aktuellen gedruckten Nachschlagewerken gelingt nicht immer wie von den Verlagsunternehmen geplant. ${ }^{?}$

\subsection{Was man für die Nutzung wissen muss}

Gelegentlich fällt dieser Abschnitt mit dem vorhergehenden zusammen. Doch gibt es u.U. auch praktische Ratschläge oder explizite Warnung vor Fehlinterpretationen und Missverständnissen, die bei der ,Weiterverarbeitung' der lexikografischenzyklopädischen Informationen in Studium, Beruf und öffentlichen Diskursen entstehen könnten. Durch diese Hinweise sollte es auch möglich sein, Argumentationen, die auf (irgend)einer Lexikoninformation aufbauen und diese als autoritative Quelle heranziehen, kritisch zu prüfen.

9 Zur jüngsten Geschichte des Brockhaus s. Keiderling 2009. 


\subsection{Bibliografie in Auswahl}

Die Auflagen und ggf. geänderten Titel des Werks einschließlich der Nachdrucke und elektronischen Fassungen (CD-Roms oder Internet-Adressen) werden dokumentiert. Zum Verständnis des Lexikons relevante Werke desselben Verfassers bzw. solche, die bei der Einordnung des lexikografischen Horizonts helfen, werden genannt. Anderweitig publizierte Forschungsüberblicke mit oft ausführlicheren Werk-Bibliografien werden vorrangig angeführt, weitere Forschungsliteratur je nach Einzelfall und Forschungslage runden die Bibliografie ab.

\section{Zum (besseren) Verständnis des lexikografischen und enzyklopädischen Prozesses}

Dieser Abschnitt wendet sich in erster Linie an LeserInnen, die wenig oder gar nicht mit Lexikografie als wissenschaftlicher Praxis und mit der damit verbundenen Theorie oder ,Metalexikografie‘ sowie mit den historischen Eckdaten der Lexikografie- und Enzyklopädiegeschichte vertraut sind. Der Abschnitt versucht zum zweiten, die auffälligsten Gemeinsamkeiten und Unterschiede in der wissenschaftlichen Betrachtung von Wörterbüchern einerseits und Enzyklopädien andererseits festzuhalten. Darüber hinaus soll sichergestellt werden, dass die teilweise divergierenden Fachausdrücke der Beitragsautorinnen und -autoren aus unterschiedlichen Fachdisziplinen da aufeinander beziehbar werden, wo (mehr oder weniger) das gleiche gemeint ist.

Nachschlagewerke enthalten eine Fülle von Daten oder besser: Informationen, die in Informationsarten, -typen oder -positionen, auch Angaben und Angabeklassen genannt, zusammengeordnet werden können; Lexika enthalten entgegen dem alltäglichen Sprachgebrauch kein Wissen, weil dieses erst durch Aneignung und eigenständige Verarbeitung der Informationen in den Köpfen der Nachschlagenden entsteht.

Man weiß, dass Nutzer, die etwa einen Brief schreiben wollen, andere Lexikon-Informationen benötigen als solche, die einen Text lesen und verstehen wollen. Die meisten Wörterbücher wollen beide Anforderungen abdecken, einige jedoch lassen einen Schwerpunkt erkennen. Sie werden dann als Produktionsbzw. Rezeptionswörterbuch oder als Kodierungs- bzw. Dekodierungswörterbuch bezeichnet.

Die charakteristischen Textfunktionen eines Wörterbuchs umfassen neben der Unterstützung bei der Textproduktion und der Textrezeption drittens die allgemeinere, didaktische Funktion des Reflektierens über Wörter und Wortschatz. Für Enzyklopädien sind funktional ansetzende Typologien kaum bekannt und in Anbetracht der Vielfalt der Erscheinungsformen auch außerordentlich schwierig. Dennoch könnten (nur) sie einer europäisch-vergleichenden Perspek- 
tive eine Grundlage liefern, wie dies lexikografische und sprachwissenschaftliche Typologien für Wörterbücher sind. Ausgesprochen gelungen und in der Beispielanalyse des Zedlerschen Universal-Lexicons erfolgreich eingesetzt scheint mir die Typologie enzyklopädischer (Sprach-)Handlungen in Schneider (2008c), die dort drei „Erscheinungsformen des Wissens“ zugeordnet werden; sie sollen hier aufgezählt und mit weiteren Belegen verknüpft, können aber nicht näher erläutert werden:

a) Wissen aus der Anstrengung zur Erkenntnis

Staunen

Sehnen

Erkunden

Kolportieren ${ }^{10}$

Sich behaupten

b) Wissen aus den Praktiken der Tradition

Sammeln

Blättern

Umschreiben

Bilden

Können ${ }^{11}$

c) Wissen aus dem Bemühen um Wirkung

Helfen

Werben

Belehren ${ }^{12}$

Predigen

10 Zur Praxis des Kolportierens und der eigenwilligen Sachverhaltsreproduktionen s. Schneider 2004. Wesentlicher Hintergrund des Kolportierens ist das Vollständigkeitsstreben der Enzyklopädien, die zu einer Zeit eine ganze Bibliothek ersetzen sollten, als deren Lektüre das Individuum zu überfordern schien. Die „Ganzheitsverliebtheit“ (Kiesow 2004: 67), parallel dazu das Vollständigkeitsideal der Sprachwörterbücher, kam im Laufe des19. Jahrhunderts an sein Ende, als die Masse des Gedruckten und Wissenswerten enorm zunahm. Ich möchte das (tendenzielle) Scheitern einiger enzyklopädischer und lexikografischer Großprojekte auf das Festhalten am Vollständigkeitsgedanken zurückführen.

11 Das Können betraf seit der Aufklärung insbesondere die traditionellen Handwerke und das modernere Manufakturwesen. Inwiefern Enzyklopädien hier mit Schwerpunktsetzungen und Ausblendungen etwa der sozialen und Arbeitswirklichkeit spezifische Konstruktionen des Drechselns, Goldmachens, Hutmachens, Strumpfwirkens und der Färberei etc. schufen, zeigt anschaulich Elkar 1995. Ebenso dürfen ,Können' und ,Nützlichkeit' nicht mit Rezepten für den Alltag der Leser gleichgesetzt werden (ebd.).

12 Das Belehren, d.h. die umfassende pädagogische Absicht wird exemplarisch schon für die frühneuzeitliche Enzyklopädie belegt bei Schmidt-Biggemann (1995: 13), sie gilt für die spätaufklärerischen Enzyklopädien und Konversationslexika des 19. Jahrhundert in noch stärkerem Maße; vgl. Albrecht 1995, bes. $241 \mathrm{ff}$. 
Man kann einwenden, dass bei diesen Typen die Perspektiven des Lexikonautors und des Lesers vermischt sind. Während es der Lexikonautor ist, der sich und die Relevanz seiner Arbeit durch Wahl bestimmter Mittel behauptet, sind Sehnen und Staunen gemeinsame Haltungen, aber das Können etwa in der Herstellung von „Schokolade mit Vanille“ (Schneider 2008c, 98) ist Sache der Leser der Enzyklopädie. Doch alles, was (auch) der Leser mit den enzyklopädischen Informationen tut, ist in dieser Typologie vom Autor intendiert und insofern in der Wahl der darstellungsformalen Mittel vorweggenommen. Die Typologie ist übernational anwendbar und formuliert die Voraussetzungen für die Darstellungsformen, die in einer Enzyklopädie jeweils gewählt werden, damit wird eine Analyse der enzyklopädischen Form vor dem Hintergrund gattungstypischer Funktionen möglich.

Schneider (2004: 93f.) zeigt, wiederum an Zedler, dass die Kombination des Kolportierens, des Belehrens und des Helfens bzw. Könnens zur Koexistenz unterschiedlicher und teils wohl auch einander widersprechender Wissenskomplexe führt, wenn etwa Schulmedizin und therapeutisches Wissen, wenn Experimentalphysik und praktisch-traditionelle Kenntnisse ein konkurrierendes Nebeneinander bilden. Die Textsorte Lexikon integriert das Verschiedene nicht. Ob sie dadurch schon in der Lage ist zu synthetisieren, wie Schneider (2004: 94) optimistisch meint, scheint fraglich; selbst in den Köpfen der selektiv lesenden Nutzer dürfte Synthese oder Integration des Unterschiedlichen die Ausnahme gewesen sein. Die textsortenspezifische Praxis des Kolportierens führt m. E. vielmehr zu einer Pluralisierung von Sichtweisen auf Dinge und Probleme, schon lange bevor die säkularisierte und traditionsskeptische Form der Enzyklopädie dies programmatisch vertrat. ${ }^{13}$

Beispiele für lexikografische Informationsarten sind: Bedeutungsumschreibung, Bedeutungs- oder semantische Paraphrase oder Definition, Worttrennungsangabe, Herkunftsangabe, Satzbeispiel, Quellenangabe u.v.m. Unter sog. Kompetenzbeispielen werden kurze, von den Lexikografen (aus ihrer Sprachkompetenz heraus) selbst gebildete Beispiele für den Wortgebrauch verstanden, sie werden unterschieden von Belegen oder Belegbeispielen, die mit bibliografisch nachgewiesenen Zitaten (meist anerkannter Autoren) identisch sind. Syntagmen sind Wortverbindungen, die i.d.R. weniger als einen ganzen Satz umfassen und die die Aufgabe haben, die grammatischen und semantischen Anschlüsse eines Worts an andere im selben Satz zu veranschaulichen. Phraseologismen, Redewendungen oder idiomatische Wendungen sind Syntagmen, die als Ganzes eine angebbare Bedeutung haben; die Bedeutung eines Phraseologismus ist ,übersummativ', d.h. sie ist nicht aus den

13 d'Alembert (1750/1989: 46) vergleicht die Enzyklopädie mit einer von mehreren existierenden Weltkarten und folgert: „so wird die Gestalt der Enzyklopädie von dem Standpunkt abhängen, den man bei der Betrachtung des gesamten Bildungswesens zu vertreten gedenkt. Man könnte sich demnach ebensoviele wissenschaftliche Systeme denken wie Weltkarten verschiedenen Blickwinkels, wobei jedes dieser Systeme einen besonderen, ausschließlichen Vorteil den anderen gegenüber aufzuweisen hätte." 
Bedeutungen der ihn zusammensetzenden Wörter erschließbar - dies macht ihre Berücksichtigung in Sprachwörterbüchern notwendig. Sog. Kollokationen sind Syntagmen aus i.d.R. zwei Wörtern (z. B. blond + Haar), die typischerweise zusammen gebraucht werden, ohne im Satz zwingend nebeneinander stehen zu müssen.

Zusammenstellung und Reihenfolge der Informationsarten stellen ein konzeptionelles Merkmal des jeweiligen Nachschlagewerks dar, das oft mit der Bezeichnung Mikrostruktur oder Artikelstruktur erfasst wird. Um verschiedenartige Informationen oder Angabeklassen (s.o.) zu identifizieren und voneinander zu separieren, werden in Nachschlagewerken eher sog. typografische Strukturanzeiger, seltener sprachlich realisierte, explizite Formulierungen eingesetzt; so ,bedeuten Fettdruck, Großbuchstaben und Kursivschrift im Lexikon etwas Spezifisches, ähnlich wie auch ein Verweispfeil anstelle eines ,siehe' oder ,vergleiche‘ textsortentypisch ist.

Die extensive Nutzung typografischer und nicht-sprachlicher Mittel im Nachschlagewerk sowie die Verwendung vieler Abkürzungen geht auf den Zwang zur bestmöglichen Ausnutzung des Druckraums zurück; das Resultat ist eine mehr oder wenige starke sog. Textverdichtung, die v.a. für noch ungeübte Nutzer ein Verstehenshindernis darstellt. Obwohl dieser Zwang im elektronischen Medium nicht mehr besteht, wird die Textverdichtung hier oft nicht aufgelöst oder gemildert.

Wörterbücher haben Wortartikel, Enzyklopädien Sachartikel, die manchmal auch Einträge heißen (nach englisch entry). Das Stichwort wird auch Lemma (Mehrzahl Lemmata) genannt; es erscheint zu Beginn eines Artikels typografisch hervorgehoben und in einer grammatisch normalisierten Form. Manche Werke haben untergeordnete Stichwörter, die Sublemma(ta) heißen. Regeln für den Ansatz der Stichwortformen aufzustellen und konsequent anzuwenden ist insbesondere bei orthografisch nicht standardisierten Sprachen ein anspruchsvoller Arbeitsschritt, der Lemmatisieren oder Stichwortansatz genannt wird. Die Abkürzung s. v. für sub verbo in der Bedeutung, unter dem Stichwort' wird in Arbeiten über Nachschlagewerke häufig verwendet; eine Variante dessen ist die Kombination von ,vgl.‘ plus kursiv gesetztem Stichwort. In Arbeiten wie den Beiträgen dieses Bands herrscht sinnvollerweise der Usus, auf Artikel zu Stichwörtern zu verweisen anstatt auf die Seitenzahlen in einem Band.

Das auch in der Geschichte dominante Ordnungsprinzip der Stichwörter ist das Alphabet. Da in der lexikografischen Theorie die Perspektive des Nutzers leitend ist, wird hier statt von Ordnungen lieber von Zugriffsstrukturen gesprochen, insofern Nutzer entweder über das Alphabet und damit über das Äußere eines Wortzeichens oder aber über die dargestellten Themenfelder und Dinge auf die Informationen ,zugreifen'. Neben alphabetischer und thematischer (oder ontischer) Zugriffsstruktur wird ferner unterschieden zwischen semasiologischer und onomasiologischer Zugriffsstruktur. Erstere geht von einer Stichwortform aus und erläu- 
tert die ihr zugeordneten begrifflichen Inhalte (Es sind meist mehrere.). Der onomasiologische Zugriff geht von einer begrifflichen Größe aus und verzeichnet die Wörter, die zum sprachlichen Ausdruck dieser begrifflichen Größe üblich sind. Nicht zwingend, aber sehr üblich ist die Kombination aus einerseits alphabetischer und semasiologischer Zugriffsstruktur/Ordnung und andererseits thematischer und onomasiologischer Zugriffsstruktur/Ordnung. Da in einem Nachschlagewerk auch mehrere Zugriffsstrukturen, etwa in verschiedenen Lexikonteilen, angeboten werden können, braucht man für die Betrachtung der Gesamtstruktur eines Nachschlagewerks gern den Ausdruck Makrostruktur.

Das häufigste und lexikontypische Ordnungsprinzip (die Zugriffsstruktur) ist das Alphabet. Tatsächlich gibt es im Zusammenhang mit den Schriftzeichensystemen verschiedener Sprachen zahlreiche Alphabetvarianten; man denke nur an die Möglichkeiten, das deutsche $\ddot{a}$ als $a e$, vor oder hinter $a e$ oder hinter $a$ einzuordnen. Für Enzyklopädien und für bestimmte Typen von Sprachwörterbüchern gab es v. a. in der Vergangenheit aber auch systematische Ordnungsprinzipien, die entweder ein Ordnungsmodell für die Welt und die Dinge oder eines für die Bedeutungen der Wörter zugrundelegten. Das erste kann man ontisch, das zweite semantisch nennen. Semantische Ordnungsmodelle zeigen die Wörterbücher von Roget (Wrede in diesem Band) und Dornseiff (Storjohann in diesem Band).

Ontische Ordnungsmodelle setzen eine im Grunde ungebrochene und von fraglosem Konsens getragene Weltordnung voraus, die für die voraufklärerischen Enzyklopädien in der Tat noch grosso modo typisch ist. Die Weltordnung war von Gott her gedacht und theologisch-systematisch ausgeformt; sie umfasste alle Lebens- und Wissensbereiche. Durch den Prozess der Säkularisierung, durch die philosophische Entdeckung, dass alles Wissen erst durch die menschliche Wahrnehmung und Erfahrung erfasst werden kann, schwand der Konsens über die eine mögliche Weltordnung, ohne dass eine andere an deren Stelle hätte gesetzt werden können (vgl. Schmidt-Biggemann 1995: 15ff.). Gewissermaßen in dieser historischen Situation führten Enzyklopädien wie die große französische die alphabetische Ordnung ein und reflektierten sogleich deren Nachteil, Sinnzusammenhänge zu zerreißen. So wird der Encyclopédie ein auf Francis Bacon zurückgehender grafischer ,Stammbaum der Wissenschaften' oder Wissensbaum ${ }^{14}$ vorangestellt, der den Nachteil des Alphabets aber kaum völlig ausgleichen kann. Das Problem wird im Vorwort d'Alemberts zur Encyclopédie ausführlich diskutiert, doch schon Zedler und Ephraim Chambers ${ }^{15}$ hatten zuvor über das Problem geschrieben (Dorn 2008: 184ff.). Vor diesem Hintergrund bekommt die enzyklopädische Praxis des

14 Vielfach abgebildet, z. B. in: http://www.physiologus.de/bilder/wissensb.gif (einges. 20.9. 2010). Zu Bacons Grundlegung vgl. d'Alembert (1750/1989: 10, 71, 116f., 122).

15 Ephraim Chambers, Cyclopaedia; or an Universal Dictionary of Art and Sciences, containing an Explication of the Terms and an Account of the Things Signified thereby in the several Arts, Liberal and Mechanical, and the several Sciences, Human and Divine, London, 1728. 
Querverweisens ein besonderes Gewicht - Diderot entwarf s.v. Encyclopédie eine regelrechte ,Philosophie des Verweises'. ${ }^{16}$

Dass noch ganz andere Ordnungsmodelle möglich und aus dem arabisch-islamischen Mittelalter bekannt sind, zeigt Biesterfeld (2004): Islamische Enzyklopädien vereinten religiöse Erbauung mit ästhetischem Genuss und Wissensvermittlung, ohne dass eine säkularisationsbedingte Trennung der drei Bereiche eintrat. Die hierzu passenden Ordnungsprinzipien waren erstens die Bildung von Vorgangs- oder Handlungssequenzen (,Herrscher und Gehorchen', ,Ratgeber am Hofe', usw.), die stark an kognitionswissenschaftliche Schema-Kategorien erinnern; zweitens die Bildung von kontrastiven Begriffspaaren wie ,Armut/Reichtum‘.

Die Verweise oder elektronischen Links von einem Artikel auf einen oder mehrere andere folgen im günstigen, historisch erst relativ spät realisierten Falle eingehenden Überlegungen und bilden insgesamt das Verweissystem, die Verweisstruktur oder auch Mediostruktur eines Nachschlagewerks. Als Verweisartikel werden solche Wortartikel bezeichnet, die nur einen Verweis auf ein anderes Stichwort oder eine andere Stichwortform enthalten. Die sprachlichen und typografischen Mittel, mit denen Verweisungen realisiert werden, heißen mediostrukturelle oder VerweisElemente. Als Ziele eines bestimmten Verweissystems können infrage kommen: Darstellungsökonomie und Vermeidung von Redundanz; partielle ,Reparatur' der durch das sinn-lose Alphabet zerrissenen Sinn- und Sachzusammenhänge eines Wissensgebiets, Konstruktion begrifflicher Ordnungen; bessere Orientierung der Nutzer beim Erkennen von Zusammenhängen. Die in Online-Medien häufig anzutreffende Praxis rein assoziativer Verweise würde man kaum als systematisch bezeichnen.

Die Stichwortmenge eines Lexikons oder Wörterbuchs ist Resultat wichtiger Auswahlentscheidungen und wird in den Beiträgen meist ausführlich charakterisiert. Dabei werden auch die synonymen Fachausdrücke Makrostruktur und Nomenklatur verwendet.

Realistischerweise kann kein Nachschlagewerk den gesamten Wortschatz einer Sprache, also die Standardsprache, die Alltags- und Umgangssprache, alle Fachsprachen und Dialekte sowie Sondersprachen abdecken. Es kann aus der Gesamtsprache, die all dies umfassen würde, allenfalls nach Kriterien wie Gebräuchlichkeit oder Nachschlagebedürftigkeit auswählen. Man stellt sich die Gesamtsprache aus einer Vielzahl von Spielarten, den sog. Varietäten zusammengesetzt vor, unter denen die herausgehobene Varietät die Standardsprache darstellt. Der hiermit synonyme Ausdruck Hochsprache wird wissenschaftlich nicht verwendet, da er eine unakzeptable Wertung zwischen einer hohen und den niedrigen Varietäten impliziert. Die Gesamtsprache wird in einer bestimmten linguistischen Perspektive auch als Diasystem bezeichnet; die diastratische Gliederung eines Dia-

16 Vgl. Albert (1995: 203); zusammenfassend zur Rolle der Ordnungsmodelle in der Geschichte der Enzyklopädik siehe Abschnitt 14.2 in Haß-Zumkehr 2001. 
systems nimmt den Sprachgebrauch sozialer Gruppen (bzw. in früherem Verständnis Schichten) in den Blick, die diatopische Gliederung ist eine räumliche in Mundarten und Regionalsprachen. Wörterbücher, aber auch Enzyklopädien hatten und haben oft einen großen Einfluss auf die Herausbildung und Etablierung einer anerkannten Standardsprache in einer Kultur, die für die überregionale Kommunikation, für Staat, Recht, Wirtschaft, Wissenschaft und Bildung grundlegende Voraussetzung ist. Sie schaffen durch Auswahl von Wort-, Laut-, Schreibund grammatischen Varianten, durch semantische Analysen begrifflicher Kategorien(systeme) und durch deren öffentlich zugängliche Dokumentation zumindest eine Referenzbasis für Diskussionen und führen letztlich einen Konsens herbei. Eine vergleichbare Funktion haben nur sehr wenige andere Texte bzw. Textgattungen, die in besonderen historischen Konstellationen weite Verbreitung finden: in der Frühen Neuzeit im deutschsprachigen Raum die Lutherbibel, später einige herausragende Rechtskodifikationen wie das Allgemeine Preußische Landrecht von Ende des 18. und das Bürgerliche Gesetzbuch vom Ende des 19. Jahrhunderts. Ähnliche Beispiele ließen sich für andere Sprachräume finden.

Da Nachschlagewerke nicht, wie man es sich von anderen Texten vorstellt, aus der reinen Einbildungs- oder Erfindungskraft der Autoren heraus entstehen, liegt ihnen eine Materialbasis zugrunde, die bei der Charakterisierung der Konzeptionen eine wichtige Rolle spielt. Sie wird auch Wörterbuchbasis genannt und kann andere Nachschlagewerke, Forschungsarbeiten und originale Sprachzeugnisse oder Quellen enthalten. Letztere sind zentral und bilden zusammen das Korpus eines Wörterbuchs. Ein Korpus bestand früher aus Belegsammlungen auf alphabetisch archivierten Zetteln (Zettelsammlungen), inzwischen zunehmend aus durchsuchbaren digitalen Texten. Die Herstellung einer Zettelsammlung geschah durch Lesen von Quellentexten, Herausschreiben der Wortumgebungen und genaue bibliografische Dokumentation der Textstelle. Dieses Verfahren heißt Exzerpieren, Exzerption und wurde meist von hilfswilligen Exzerptoren erledigt.

Das Nachschlagewerk, das aus mehreren, oft umfangreichen Bänden besteht, wurde meist nicht auf einmal, sondern in Teilen, entweder in Bänden oder in noch kleineren Einheiten, sog. Lieferungen oder Faszikeln publiziert. Die Käufer ließen die (meist vier oder sechs) Lieferungen später zu einem Band zusammenbinden. Außer der aus allen Artikeln gebildeten Makrostruktur enthält ein Nachschlagewerk weitere, in ihrer Wichtigkeit und Funktion oft unterschätzte Textteile (Vor-, Nachwort, Register, Grammatiken, Listen usw.), die Paratexte oder Umtexte heißen.

Bei der Benutzung historischer Lexika muss man damit rechnen, dass in den Laut-Buchstaben-Zuordnungen v.a. bei c/k, th/t, y/i, ey/ei Abweichungen von der heutigen Orthografie auftreten. Man sollte die Stichwörter also in mehreren denkbaren Schreibweisen an unterschiedlichen Orten in der alphabetischen Reihe suchen. Dorn (2008) zeigt anschaulich, wie gravierend und weit über orthografische Aspekte hinausreichend das Problem des Stichwortansatzes in historischen Nach- 
schlagewerken für heutige Nutzer sein kann; eine Kompensation ist jedoch durch eine inhaltserschließende Digitalisierung möglich.

\section{Europa als, Wissensraum'? Thesen zum innereuropäischen Zusammenhang von Lexikografie und Enzyklopädik}

Von einer systematischen Beschäftigung mit den innereuropäischen Bezügen von Lexikografie und Enzyklopädik kann bisher kaum die Rede sein. Allerdings sind immer wieder punktuelle Beobachtungen festgehalten worden, die zumindest unzweifelhaft belegen, dass Lexikonautoren unterschiedlicher nationaler und sprachlicher Zugehörigkeit, von einander Kenntnis nahmen'. Bis weit ins 19. Jahrhundert hinein gehörten Autoren von Nachschlagewerken in ganz Europa zu einer relativ schmalen intellektuell tätigen Gruppe der Gesellschaft, die über das gemeinsame Fundament humanistischer Bildung verfügten und die von einer im Kern gleichen Tradition griechisch-lateinischer, auch hebräischer Text- und Kulturkenntnis ausgingen.

Der Ausdruck Wissensraum ist zugegebenermaßen ein Schlag- und Modewort, das hier nicht unreflektiert verwendet werden sollte. Es handelt sich um eine Metapher, die sich auf mehr bzw. anderes beziehen lässt als auf topografische Größen. Bernd Thum hat wiederholt dafür plädiert, den Begriff des Wissensraums

auch funktional [zu] verstehen, als Zone verdichteter Beziehungen, die schließlich auch zu festen gemeinsamen Wissensbeständen führen. Durch Verdichtung entstehen neue Informations- und Wissensstrukturen. Dies verändert nachhaltig die gesamte Wissensordnung einer Kultur, schafft dynamische kulturelle Identitäten, fördert dadurch bei allen Partnern die Modernisierung und erleichtert die Verständigung über die großen Aufgaben, die gemeinsam zu bewältigen sind. Voraussetzung ist, dass die neuen Wissensräume auch kulturelle Informationen, Wissen über kulturelle Prozesse und Strukturen mit einschließen. (Thum 2009: 82)

Von gemeinsamen Wissensbeständen europäischer Lexikografen und Enzyklopädisten (aufgrund verdichteter Beziehungen?) kann vor allem beim historischen Wissen gesprochen werden, so in Bezug auf die Französische Revolution, die Nationalbewegungen des 19. Jahrhunderts, die beiden Weltkriege des 20. Jahrhunderts und die Ost-West-Teilung der Welt. Doch werden sich Perspektiven und Fokussierungen, ja selbst eine Faktenauswahl in den jeweiligen Nationen, bei den Werken und auch bei den individuellen Autoren deutlich voneinander unterscheiden.

Die in der Forschung beispielhaft genannten punktuellen Auffälligkeiten konzentrieren sich auf das 19. und beginnende 20. Jahrhundert und zeigen in der Gesamtschau einen durchaus plausiblen Zusammenhang: Umfangreiche Sprachenkenntnisse von Wissenschaftlern und Schriftstellern waren in erster Linie durch Bücher vermittelt, unter denen Sprachwörterbücher und Grammatiken eine 
herausragende Rolle spielten, insofern sie den Zugang zu den nationalkulturellen Literaturen eröffneten. Von dieser vergleichenden Kenntnis europäischer Schriftzeugnisse $^{17}$ aus eröffneten sich mehrere Erkenntniswege, die in unterschiedlicher Gewichtung den Konnex und die wechselseitige Identifizierung von Sprache, Geschichte und Nation historisch-genetisch zu belegen schienen und entsprechende Argumentationen auch in die öffentlichen Diskussionen ihrer jeweiligen Länder einbrachten, wo sie wie am deutlichsten in Deutschland zustimmend begrüßt oder auch wie am Beispiel der Ukraine erkennbar von der Staatsmacht abgelehnt und unterdrückt wurden.

Wenn man nicht bei der Sammlung solcher Beobachtungen aus der europäischen lexikografiehistorischen Literatur stehenbleiben, sondern die Möglichkeiten eines ,europäischen Wissensraums' überblicken will, muss systematisch nach den übrigen Elementen oder Ebenen der europäischen Dimension gefragt werden. Die nachfolgende Auflistung versucht, Forschungsstand und -lücken zumindest zu umreißen:

\subsection{Gemeinsame Referenzwerke}

Dass gerade die großen lexikalischen und enzyklopädischen Unternehmungen mit Vorliebe gerade aus Werken anderer europäischer Länder bzw. Sprachen schöpften, wird in den Beiträgen dieses Bands mehrfach belegt. Die gemeinsamen Referenzwerke wechselten zwar nach Epoche und Intention der Autoren, doch bildete sich ein gemeinsamer Kern von Werken heraus, zu dem v.a. das Crusca-Wörterbuch, Johnsons Dictionary of the English Language, Emile Littrés Dictionnaire de la langue française (1863-1872), die große französische Enzyklopädie, die Encyclopaedia Britannica und das Grimmsche Wörterbuch zählen. Als gemeinsame Referenzwerke müssen aber auch die eher ungenannten Arbeitsinstrumente der Lexikonautoren gelten wie Franz Passows Handwörterbuch der griechischen Sprache (1819-1823) und eine Art lexikografische Arbeitsanleitung desselben Autors, diverse zweisprachige Wörterbücher, Personenlexika und mythologische Lexika zur griechisch-römischen Antike wie zum Mittelalter. Auch die verbreitete Kenntnis herausragender Werke der Literatur der jeweiligen Nachbarländer einschließlich ihrer Bibelübersetzungen gehört noch hierzu.

Besonders bei Enzyklopädien ist das Prinzip des Kompilierens von Fachliteratur immer wieder beschrieben worden; auch Sprachwörterbücher wurden z.T. voneinander ab- und umgeschrieben. Alle diese Formen lassen sich als kulturelle Transformationen und Übersetzungshandlungen begreifen, gleichgültig, ob dabei von einer Sprache in eine andere oder von einem Fachtext in einen allgemeinverständlichen Text übersetzt wurde (Schneider 2008b: 161). Beispielsweise haben

17 Das bekannte große Interesse des 19. Jahrhunderts an Quellen mündlicher Überlieferung mündete ja ebenfalls in schriftliche Dokumentationen von Volksdichtung. 
der Enzyklopäde Krünitz und seine Nachfolger nachweislich ihr Wissen aus Zeitschriften aus dem gesamten europäischen Raum geschöpft; dies war eine Möglichkeit, den aktuellen Wissensstand zu erfassen. Neben heimischen preußischen Zeitschriften und anderen aus dem deutschsprachigen Raum werteten sie ein internationales Spektrum von Zeitschriften aus, das sich von England, Frankreich, den Niederlanden und Spanien, Italien über Skandinavien bis nach Polen und Russland erstreckte. Ein nicht zu unterschätzender Motor dieser kulturellen Übersetzungen war und ist womöglich immer noch das ökonomische Interesse von Verlegern, die davon ausgingen, dass sich die in einem Nachbarland erfolgreiche Enzyklopädie (z.B. von Chambers) per Übersetzung in die eigene Sprache auch im eigenen Land zu einem ,Renner' entwickeln würde, und zwar kostengünstiger als im Original. Regelmäßig zeigte sich aber auch, dass Enzyklopädien sich nicht allein durch Sprachübersetzung herstellen lassen und dass immer auch eine kulturelle Adaption notwendig ist.

Wenn Fachtexte bzw. ihre Inhalte für Enzyklopädien und v. a. für die Konversationslexika des 19. Jahrhunderts in eine allgemeinverständlichere Darstellung transformiert werden, stellt sich die Frage, ob damit regelmäßig Präzision und Differenziertheit abnehmen. Remenyi (2008) beantwortet die Frage am Beispiel der Mathematik von Christian Wolff im Zedler'schen Universal-Lexicon mit ,Nein', denn aus Referenztexten werden viel eher Ausschnitte samt der originalen Fachterminologie wörtlich übernommen als umformuliert, wie dies auch für andere Enzyklopädien gilt. Neben arbeitsökonomischen Gründen möchte ich hierfür auch die Alternativlosigkeit der deutschen mathematischen Fachsprache in jener Epoche anführen. Die Leistung eines Christian Wolff in der Herstellung einer bis dato lateinischen Fachsprache mit den Mitteln der deutschen Sprache konnte kaum von einem enzyklopädischen Autor ,nebenbei‘ variiert und in seiner Verständlichkeit gesteigert werden. Ob die ,Eroberung' der eigenen Volks- bzw. Nationalsprache für wissenschaftliche Bereiche, in denen eine andere Sprache (Latein, heute vielfach Englisch) üblich war, auch für andere Ländern anzunehmen ist, und ob eine solche Eroberung eher auf der Ebene der Referenzwerke oder auch in den Enzyklopädien selbst vorangetrieben wurde - ob sich diese Konstellation und dieses Verfahren also in Europa wiederholte, muss an dieser Stelle eine offene Frage bleiben.

Für andere Wissensgebiete wie die Mathematik scheint die lexikontypische Regel, dass durch kolportierende Kombination von Auszügen aus Fachtexten etwas Neues, nämlich ein kontextualisiertes und anwendungsbezogenes Sachwissen entstand, jedoch bestätigt zu werden, wie Schneider (2004: 96f.) am Beispiel des Stichworts Vanille zeigt. Der scheinbare Widerspruch im Umgang mit dem Referenzwerk der Wolffschen Mathematik (wörtliche Übernahme) und den Referenztexten für Vanille (Transformation) ließe sich dahingehend auflösen, dass die Lexikonautoren in beiden Fällen das Ziel der größtmöglichen Nähe zum Leser verfolgten, wobei Nähe zum Leser sowohl sprachliche Nähe als auch Nutzanwendung, Interesse an exotischen Genüssen u.v. m. bedeuten kann. 
Nähe zum Leser hieß u. U. auch Öffnung traditionell nicht-öffentlicher Wissensbestände. Hohrath (2004) hat die Transformation militärischen Wissens aus französischen Fachbüchern in den Lexika von Zedler, Krünitz und in der französischen Encyclopédie untersucht und festgestellt, dass das öffentliche, gebildete Interesse an dem, was Offiziere können und wissen sollten, das Berufsbild des Offiziers selbst veränderte: vom Kriegshandwerker zum Militärfachmann mit Ingenieurskenntnissen.

Es stellt sich die Frage, ob unterschiedliche Referenzwerke zu einem gesamteuropäisch relevanten und tradierten Wissensgebiet wie z.B. der Musik zu divergenten Konzeptionen und „Strategien der Wissensvermittlung“ führten. Bandur (2004, bes. 242f.) bejaht dies: Im Deutschen bei Zedler ist Musik primär ein geschichtlich-chronologisch fortentwickeltes Konzept. Im Französischen bei Rousseau, der das Themenfeld in der Encyclopédie bearbeitete, ist sie ein ästhetischempfindungsorientiertes und im Englischen in der Encyclopaedia Britannica ein Regel- und Kenntnissystem. Obwohl hier individuelle Präferenzen der jeweiligen Lexikon-Autoren nicht auszuschließen sind, spricht offensichtlich einiges für die Annahme nationalkultureller Typik. Das Beispiel zeigt aber auch, welch hohe methodische Anforderungen an die Untersuchung gesamteuropäischer Wissensbestände gestellt sind.

\subsection{Sprachenkenntnisse der Autoren}

Die zumindest passiven Kenntnisse fremder Sprachen waren bis ins 20. Jahrhundert hinein bedeutend breiter und wohl auch tiefer als heutige, reizüberflutete Zeitgenossen es sich vorzustellen vermögen. Kirkness (2011) hat für Jacob Grimm und Wilhelm Grimm anhand der von ihnen verfassten Bände des Deutschen Wörterbuchs die Menge der indoeuropäischen Sprachen und die Häufigkeit ihrer Erwähnung festgestellt und kommt auf eine Anzahl von 26. Es handelte sich hierbei natürlich nicht nur um lebende Sprachen, so dass die Sprachkenntnisse der Brüder Grimm nicht zuletzt über Wörterbücher und Grammatiken vermittelt waren. Kirkness (2011) ermittelte weiter, dass ca. 220 Sprachwörterbücher in ihrem Besitz gewesen sind - zu ,größeren' Sprachen wie Latein oder Englisch 23 bzw. 12, aber auch je einzelne Wörterbücher zu Sprachen wie Gälisch, Bretonisch und Baskisch. Nachgewiesen sind ferner Bibliotheksausleihen Jacob Grimms, darunter besondere Wörterbuchtypen, z.B. ein italienisches Synonymen-Wörterbuch, aber auch außereuropäische Wörterbücher, z.B. zum Mongolischen.

Auch für viele andere Lexikografen Europas gilt, dass ihre Sprachkompetenzen im Kern die antiken Sprachen einschließlich Hebräisch, im zweiten Kreis die jeweiligen Nachbar- und Kontaktsprachen und darüber hinaus oft noch weitere, vermutlich eher lesend als sprechend beherrschte Sprachen umfasste. 


\subsection{Foren für übernationale, europäische Diskurse}

Ideen und Konzeptionen für große Lexika, die kaum mehr von einzelnen Individuen erarbeitet werden können, wurden schon früh in Gelehrtenzirkeln, in ihren Publikationen und ihren privaten Korrespondenzen formuliert und diskutiert. Eine nationale Abschottung solcher Foren gegeneinander war und ist immer noch undenkbar, auch wenn die Initiativen oft von regionalen oder nationalen KernGruppen ausgingen. In der Wissenschaftsgeschichte der europäischen Philologien und auch der Geschichtswissenschaft(en) werden Zeitschriften mit ihrem Rezensionswesen, mit in ihnen dokumentierten Konferenzen und Briefwechseln aufmerksam untersucht, insbesondere seit man sich nicht mehr nur mit Wissenschaftler-,persönlichkeiten', sondern mit den sie verbindenden Diskursen befasst. Die fortschreitende Digitalisierung solcher Zeitschriften und weiterer historischer Quellen erleichtert die Suche nach lexikografisch-enzyklopädischen Diskussionen beträchtlich und belegt ihre Existenz. ${ }^{18}$

Ein Beispiel für die mindestens europäische, wenn nicht sogar weiter ausgreifende Transnationalität dieser Diskussionsforen und ein Beispiel dafür, dass hierbei auch eine besondere lexikografische Absicht verfolgt werden kann, ist die 1884 gegründete Zeitschrift Archiv für lateinische Lexikographie und Grammatik mit Einschluss des älteren Mittellateins. Als Vorarbeit zu einem Thesaurus linguae Latinae. ${ }^{19}$ Der Herausgeber Eduard Wölfflin war ab 1894 einer der leitenden Autoren des ThlL (siehe Schröder in diesem Band). Die Zeitschrift nennt die Funktion der vorbereitenden lexikografischen Reflexion sogar in ihrem Untertitel. Der Blick in das Inhaltsverzeichnis eines beliebigen Bandes zeigt, dass neben lateinischsprachigen und deutschsprachigen Beiträgen mindestens auch eine Reihe von französischen, italienischen und englischen Autoren lexikografische Themen auch allgemeinerer, d.h. nicht nur auf das Lateinische bezogener Art behandelten. Der neunte Band von 1896 enthält zu Beginn ein „Verzeichnis der Gelehrten, welche Beiträge zu Band I - IX geliefert haben“; darunter befinden sich Namen aus weiteren Ländern bzw. Regionen: den Niederlanden, den USA, der Schweiz, Posen, Breslau, Krakau, Schlesien, Königsberg, Wien, Graz, Innsbruck, Helsingfors (Helsinki), Schweden, Portugal, der Ukraine, dem Elsass. Im Fall des wissenschaftlichen Lexikografen Hermann Paul lässt sich belegen, wie seine Rezeption der in Wölfflins Archiv stattgehabten Diskussionen sein Werk Prinzipien der Sprachgeschichte (1888) sowie sein Wörterbuch geprägt hat (Näheres in Haß-Zumkehr 2004).

18 Auf der Webseite http://www.ub.uni-bielefeld.de/diglib/aufklaerung/index.htm (zuletzt einges. am 20.9.2010) sind 160 deutschsprachige Zeitschriften des 18. und 19. Jahrhunderts durchsuchbar; nach der Eingabe der Suchwörter, Wörterbuch', ,Lexikon' und ,Enzyklopädie (in verschiedenen Schreibweisen) lässt schon die Trefferliste erahnen, welch intensive Diskussionen das Thema auf sich zog.

19 Der vierzehnte Band (1906) ist von google digitalisiert: http://www.archive.org/stream/ archivfrlateini05wissgoog\#page/n5/mode/1 up, zuletzt eingesehen am 20.09.2010) 
Ein weiteres Forum, das Deutsch mit modernen Fremdsprachen verknüpfte, war das Archiv für das Studium der neueren Sprachen und Literaturen, gegründet 1846. Hier publizierte etwa Daniel Sanders, Kritiker und lexikografischer Konkurrent der Brüder Grimm, nicht wenige Beiträge, stellte sie zur Diskussion und rezensierte andere. Auf diese Weise bereitete er die Konzeption mehrerer seiner eigenen Wörterbücher vor.

Eine gezielte Untersuchung wenigstens der wichtigsten dieser internationalen Diskussionsforen im Hinblick auf lexikografische und enzyklopädische Themen, auf Ideenaustausch und diskursive Verfertigung von Konzeptionen für Nachschlagewerke steht noch aus.

\subsection{Gemeinsames wissenschaftliches Paradigma; \\ Theorie und Methode}

Jeder Lexikograf, der mit einem eigenen Wörterbuchprojekt beginnen wollte, suchte nach Orientierung in Fragen der Methodik und auch nach Hinweisen zur Lösung der zahlreichen praktischen Schwierigkeiten, die immer auftreten. Doch kaum eine Methode ließ sich je kopieren; stets waren Adaptionen an die eigene Intention und an die Rahmenbedingungen im eigenen Land und in der je neuen historischen Situation notwendig. ,Nahe' Adaptionen der Methoden waren möglich innerhalb der Aufklärungsepoche und innerhalb des historisch-entwicklungsgeschichtlichen Paradigmas, nicht aber zwischen beiden. Offensichtlich wurde die Grenze, die zwischen der ,semantischen' Lexikografie des achtzehnten und der ,etymologischen' des neunzehnten Jahrhundert bestand, nicht überschritten, abgesehen von den wenigen Ausnahmen kleiner Länder mit einer relativ späten Entwicklung ihrer National- und Standardsprache; sie mussten ihr Potenzial bündeln und scheinen konzeptionell und methodisch den Weg vom achtzehnten ins zwanzigste Jahrhundert oft schneller und ohne Umweg über historische Monumentaldokumentation gefunden zu haben.

Die historisch-genetische Beschreibung des Wortschatzes weist ausgehend vom Jahrhundert der europäischen Nationalbewegungen eine beispiellose Erfolgsgeschichte auf. Viele europäische Nationen und Kulturen adaptierten einiges von dem, das die Brüder Grimm und das Oxford English Dictionary vorgeführt hatten. Grund war nicht nur das gesellschaftliche Interesse an Wörterbüchern, die die Frage nach der Herkunft der Wörter ins Zentrum stellte, sondern nicht zuletzt die enge Verbindung der Lexikografie mit dem innovativen Wissenschaftsparadigma der historisch-vergleichenden Philologie seit Anfang des 19. Jahrhunderts. Es war diese Verbindung, die die europaweite Erfolgsgeschichte begründete. Allerdings darf die grobe Unterscheidung zwischen historischem und rationalistisch-aufgeklärtem Paradigma nicht über Gemeinsamkeiten und andersgelagerte Differenzierungen auf subtileren Ebenen der lexikografischen Programmatik hinwegtäuschen. Ein Beispiel: 
Trench, führender Kopf des Oxford English Dictionary, berief sich mit seiner Intention, „the biography of a word“ geben zu wollen, auf Franz Passow, der dafür den Ausdruck „Lebensgeschichte“ gewählt hatte. ${ }^{20}$ Ähnlich und doch anders bestimmten die Brüder Grimm ihre Methode als „Naturgeschichte der Wörter“.21 Während Lebensgeschichte und biography mit Bezug auf Wörter konzeptuelle Metaphern darstellen, („Wörter sind wie Menschen“), knüpft Grimms Bezeichnung Naturgeschichte an eine innovative Perspektive der damaligen Naturwissenschaften an; sie reklamiert gewissermaßen, Wörter seien natürliche Organismen, die einem inneren Bauplan folgen und dieser Bauplan könne durch moderne Wissenschaft entschlüsselt werden. Soweit ging die Adaptation der Grimmschen Idee durch das $O E D$ also nicht, und doch findet sich auch im OED der Versuch, das Wörterbuchunternehmen als der ,modernen' Wissenschaft zugehörig zu markieren. Laut Mugglestone (in diesem Band) gebrauchte Murray für die eigene Tätigkeit nämlich die Bezeichnung philological science anstelle von humanities. Gemeinsam war den nationalen lexikografischen Konzeptionen zwar nicht die Metaphorik, aber doch der Anspruch, aus dem Handwerk des Wörterbuchmachers vergangener Zeiten eine moderne Wissenschaft zu machen.

Aus Kirkness' (2011) Belegen für die intensive wechselseitige Kenntnis und Nutzung der Werke der lexikografischen Kollegen Jacob und Wilhelm Grimms in Europa und anderen Teilen der Erde lässt sich zweifelsfrei schließen, dass alle denkbaren Aspekte, auch die Artikelstrukturen, als Anregungen für die eigene Praxis wahrgenommen wurden.

Zgusta 1991 hat die Artikelstruktur des Grimmschen Deutschen Wörterbuchs mit denen von Richardson 1836, Passow, Littré, des Wörterbuchs der niederländischen Sprache und des Oxford English Dictionary verglichen. Da Zgusta sich jedoch auf strukturelle Aspekte konzentriert, bleibt die m. E. ganz wesentliche Bedeutung der Korrelation zwischen sprachideologischer Funktion des Wörterbuchs und Form der Wortartikel zu schwach konturiert. Die äußere Form eines Wörterbuchs - Anordnungsweisen, Artikelstruktur und Typographie - kann von sehr kontingenten Bedingungen wie Verlagsinteressen, Kalkulation der Herstellungskosten und Vermarktungsaspekten beeinflusst sein. ${ }^{22}$ Erst vor dem Hintergrund allgemein ideologischer, bildungstheoretischer und sprachtheoretischer Voraussetzungen des Wörterbuchs kann die lexikografische Entscheidung für die Artikelstruktur wie die für eine Reihe anderer Eigenschaften (z.B. Stichwortauswahl, Stichwortansatz, Verweisprinzipien) hinreichend erklärt werden. Der transnationale Diskurs der Lexikografen betraf weit mehr als diese methodischen Details und sollte auch an anderem als ihnen festgemacht werden.

20 S.o. und Mugglestone in diesem Band; Kirkness 2011.

21 Wilhelm Grimm, Rede über das Deutsche Wörterbuch (1846), in: Grimm/Grimm 1985: $232 \mathrm{f}$.

22 Detailliert gezeigt am Beispiel von Daniel Sanders in Haß-Zumkehr 1995. 
Für weitere Belege der Anschlussfähigkeit und Anbindung eines wissenschaftlichen Paradigmas an die politische Kultur, insbesondere in Gestalt der Nationalbewegungen im 19. Jahrhundert wird hier auf die Beiträge verwiesen. Doch ging die vermeintliche Gleichung ,eine Nation - eine Sprache - ein Nationalwörterbuch'selten auf. Die Bewegung des sog. Skandinavismus mit der Konstruktion einer länderübergreifenden, nordischen Identität' berief sich auf die historische Sprachforschung, die das Isländische als nordische Ursprache identifiziert hatte. Gleichzeitig lieferte dieselbe Sprachforschung aber auch Argumente für die Konstruktion einer dänischen Identität, und zwar sowohl durch die lexikografische Kodifikation einer gesamtdänischen Standardvarietät als auch durch wissenschaftlich unterstütze Pflege der dänischen Dialekte (Monsson 2005: 1454, auch Venås 2005).

Die sprachideologischen Voraussetzungen der Lexikografien im 20. und 21. Jahrhundert sind ganz andere; der Zusammenhang zwischen Sprachideologie, verstanden als der Komplex gesellschaftlich verbreiteteter Vorstellungen über Sprachen und Nationen, und Wörterbüchern gilt aber weiterhin. Ein nationalsprachlicher Wortschatz wird heute anders konstruiert als im Zeitalter der Nationalbewegungen: Simpson (2004) zeigt am Beispiel des Oxford English Dictionary anschaulich, wie die Perspektive auf den zu beschreibenden (hier den englischen) Wortschatz geändert werden kann. Die Revision des OED im Jahre 2000 hat das Wörterbuch in methodischen Details, v.a. in der Etymologie und in der Definition dessen, was als Lexem der englischen Sprache gilt und ins Wörterbuch aufgenommen wird, aber auch in Angaben zur Aussprache, europanäher gemacht. Lehnwörter, Lehnbildungen und andere Arten der Übernahme aus anderen europäischen Sprachen werden jetzt deutlicher als solche markiert, sie erscheinen nicht mehr als Einzelfälle und Ausnahmen, sondern als systematisch eingebundenes und wichtiges Element des englischen Wortschatzes. Eine ähnliche Tendenz zeigt sich im spanischen Akademiewörterbuch (DRAE) seit den 1950er Jahren, als den relativ zahlreichen arabischen Etyma des spanischen Wortschatzes durch ein angemesseneres Transliterationssystem Rechnung getragen wurde (vgl. Lebsanft in diesem Band). Der Perspektivenwechsel des $O E D$ in Richtung Interkulturalität gelingt u.a. dadurch, dass nicht nur hochliterarische Quellen, sondern vermehrt Reiseliteratur, Übersetzungen und Sachtexte exzerpiert werden, aber auch durch Erweiterung des kulturellen Kontextes der Wörter. Ein Beispiel wie das folgende lässt sich durchaus verallgemeinern:

The fact that the first English usage derives from a translation of a text written in Latin by a European writer, and actually referring to Pliny, is a clear indication that the term natural history is not a native creation within English! [...] When additional European information is provided for what may otherwise appear to be native English compounds the true position of English amongst the other European languages in the Renaissance and later begins to appear. (Simpson 2004: 67) 
Man hat sich also den Wortschatz einer Sprache, so wie er in einem Wörterbuch dokumentiert ist, als eine Konstruktion vorzustellen. Die Sammlung und Kommentierung der Wörter kann so angelegt werden, dass der Wortschatz als eine relativ autonome, von äußeren Einflüssen relativ isolierte Größe erscheint. Er kann aber auch als eine in vielfachen Wechselwirkungen stehende Größe verstanden und dargestellt werden.

\section{5 Ähnliche Werksymbolik}

Wörterbücher sowie Enzyklopädien sind geprägt durch die Funktion und den Wert, der ihnen in einer Gesellschaft zugeschrieben wird. Dieser Stellenwert drückt sich pointiert in Metaphern aus - Metaphern, die in allen europäischen Lexikografiegeschichten vorkommen und vielleicht ein weiteres Mosaiksteinchen im europäischen Wissensraum darstellen. Es sind drei Metaphern, die einem hier begegnen:

Die erste ist die des Wörterbuchs als Richtschnur oder gar personifiziert als Sprachrichter. Diese Metapher repräsentiert die präskriptive, und damit in der Regel eine ältere Tradition jeder Lexikografiegeschichte, die gebunden war an die Etablierung und Sicherung einer nationalen Standardsprache. In dieser Konstruktion ergibt sich für die Lexikografen selbst die Rolle der Sprachautorität, die wegen ihres Wissens und ihrer Urteilskraft bewundert werden.

Die zweite Metapher ist die des Schatzhauses, lateinisch thesaurus. Das Wörterbuch wie die Universalenzyklopädie bewahrt gewissermaßen die ,eigentlichen Reichtümer, das Gold und die Edelsteine ,des Volkes' auf. Entsprechend prestigeträchtig müssen die zitierten Schriftsteller sein, Gebrauchstexte kommen nicht infrage. Wer hier nachschlägt, öffnet eine Truhe und ist bereit, deren Inhalt zu bewundern, und erwartet kaum, ihn kritisch prüfen zu müssen. Die politische Relevanz einer solchen Konzeption liegt auf der Hand und kann an zahlreichen Beispielen aus der ersten Hälfte des 20. Jahrhunderts nachvollzogen werden. Das Schatzhaus hat seinen Wert selbst dann, wenn es ungeöffnet im Regal steht; wertvolle und aufwändig gestaltete Einbände sind angemessen. Diese metaphorische Konzeption des Wörterbuchs bezog und bezieht sich auf die überbordenden Wortschatzdokumentationen seit Ende des 19. Jahrhunderts. In dieser metaphorischen Konstruktion haben Lexikografen den Habitus des patriotisch-aufopferungsvollen Arbeiters, der dienend hinter das Werk zurücktritt.

Die dritte Metapher ist v.a. an Enzyklopädien gebunden, dominiert heutzutage aber alle Arten von Nachschlagewerken: Informationsspeicher. Zwar liegt der Ursprung der Metapher in der Landwirtschaft, mithin in längst überholten europäischen Epochen, doch scheint die heute wesentlichere Assoziation die des Gehirns und die des Computers zu sein, da beiden das Speichern von Information zugeschrieben wird. In dieser konzeptuellen Metapher ist v.a. der Nutzen des Inhalts impliziert. Erst die Nutzer machen das Gold (Wissen) aus dem Stroh der bloßen 
Informationen. Hier besteht die Gefahr, Nachschlagewerke als bloße Datensammlungen misszuverstehen. Aufgabe und Leistung der Lexikografen verschwinden nahezu, sie scheinen nur die Erntearbeiter oder Daten-Transporteure zu sein und folgerichtig wird tendenziell versucht, sie durch Computerprogramme zu ersetzen.

\subsection{Technisch-medial und ökonomisch ähnliche Bedingungen}

Die meisten Lexikografiegeschichten zeigen, dass die Rolle und der Einfluss von Verlegern systematisch unterschätzt wurden. Spätestens seit der Aufklärungsepoche waren es regelmäßig Verlage, die nach Autoren für ihre Projektideen suchten. ${ }^{23}$ Jacob und Wilhelm Grimm wurde das Projekt Nationalwörterbuch von drei, unabhängig voneinander agierenden Verlegern vorgeschlagen. Die Verlage überdauerten auch so manches Lexikografenleben und sorgten, neben Mäzenen und staatlichen Institutionen, für Kontinuität über Generationen hinweg. Selbstverständlich stand ihr Verständnis für das Entstehen von Märkten im Hintergrund. Der enorme Anstieg der Alphabetisierungsquote und der Menge der Druckerzeugnisse als Folge der Aufklärung in der ersten Hälfte des 19. Jahrhunderts ließ Erfolgsgeschichten wie die des Brockhaus zur Motivation weiterer Großprojekte werden. Zwischen 1809 und 1870 stieg die Zahl der Exemplare pro Auflage von 2000 auf über 3000000 (Haß-Zumkehr 1995: 286). Zur Bildungseuphorie der Gesellschaften kamen technische Innovationen, die die Massenproduktion von Druckerzeugnissen erlaubten und ab Ende des 19. Jahrhunderts auch die Einbindung aufwändigerer Abbildungen. Diese Rahmenbedingungen dürften überall in Europa ähnlich, wenn auch zeitlich versetzt abgelaufen sein.

Es ist klar, dass das Internet-Zeitalter die technisch-medialen Bedingungen von Nachschlagewerken global angleicht. Dennoch sind bei näherem Hinsehen die Situationen nicht überall gleich. Sprachen mit etwa weniger als 5 Mio. Sprechern können nur über relativ kleine Materialkorpora verfügen. Wenn aber die Basis der lexikografischen Arbeit schmaler und weniger differenziert ist, ergeben sich zwangsläufig andere Methoden und Ergebnisse.

\section{7 Ähnliche sprach- und bildungshistorische Kontexte}

Wechselwirkungen mit der historischen Situation, in der sich eine Sprache gerade befindet, betreffen Wörterbücher, kaum Enzyklopädien. In allen europäischen Gegenden waren und sind Wörterbücher das erste und wichtigste Instrument einer aktiven Sprachentwicklung, d.h. Instrument von Sprachpolitik, Sprachkultur und Sprachlernen. Generell lassen sich drei Phasen des jeweils spezifischen $\mathrm{Zu}-$

23 Vgl. Darnton (1993) zur ökonomisch-politischen Geschichte der französischen Enzyklopädie. 
sammenspiels von Sprachgeschichte einerseits und Wörterbüchern andererseits erkennen.

Eine verbreitete und fraglos plausible Auffassung geht davon aus, dass das sprachliche und damit weitgehend auch das kulturelle Fundament aller zu Europa gehörenden Länder und Regionen in der lateinischen Sprache liege, die ihrerseits auf dem Griechischen fuße. Die europäischen Volkssprachen haben sich in einem insgesamt breiten Zeitraum zwischen dem späten Mittelalter und dem 18. Jahrhundert durch Herausbildung eigener Leitvarietäten vom Lateinischen ,emanzipiert ‘ ein Prozess, bei dem Leittexte wie Wörterbücher und andere Wissenssummen eine wichtige Rolle spielten, der ansonsten aber jeweils sehr spezifisch war und nur mit einigem Skrupel allgemeingültig formuliert werden kann. In der ersten Phase des Zusammenspiels von Sprachgeschichte und Wörterbuch begann die Emanzipation der jeweiligen Volkssprache vom Latein und parallel damit die Diskussion um die Wahl bzw. Festlegung der anerkannten Leitvarietät. Dies war die Phase allgemein sprachreflexiver und v.a. grammatischer Abhandlungen. In den meisten europäischen Ländern gehört diese Phase ins (späte) Mittelalter, doch gibt es sie u. U. auch später, als Diskussion um die Leitvarietät ohne gleichzeitige Ablösung des Lateins, dessen Rolle durch irgendeine andere Verkehrssprache übernommen wird.

In der Erforschung des lateinischen Fundaments europäischer Sprachen wurde für eine Tagung 1994 der Begriff des Eurolateins geprägt; die Tagung und der sie dokumentierende Band (Munske/Kirkness 1996) zeigten, wie zu erwarten war, im Detail mehr spannende Fragen als abschließendes gesichertes Wissen auf. Die Grundthese jedoch, dass es dieses Fundament gibt, ja, dass es bis heute weitreichende Folgen hat, steht nicht zur Disposition. Pörksen (1999) geht von dieser These aus: Europa fällt im Hinblick auf Gemeinsamkeiten der Sprachgeschichten der Volks- bzw. Nationalsprachen und -kulturen mit dem Raum des Lateins zusammen, und infolgedessen brauchen wir, so Pörksen, eine vergleichende europäische Sprachgeschichte, die den vielfältigen Bezug der europäischen Sprachen auf lateinische Vorbilder - vom Wortschatz über die Syntax bis hin zu Textmustern zugrundelegt. Der Raum, den die lateinische Sprachtradition konstituiert, reicht für Pörksen bildlich von Kiew bis Lissabon (Pörksen 1999: 662).

Man sollte aber nicht aus den Augen verlieren, dass bis auf die kognitiv-begriffliche Ebene hinunter Jahrhunderte lang wichtige Austauschbeziehungen der lateinisch kommunizierenden Welt mit der arabisch kommunizierenden existierten, die sich, in den europäischen Wortschätzen sedimentiert, bis heute erhalten haben. Der Europa insbesondere über das Spanische eröffnete Zugang zu arabischem Wissen und aus dem Arabischen stammenden Begriffskategorien ist wohl nur ein Beispiel dafür, dass Europa auch nicht-lateinische Wurzeln besitzt. Ein anderes Beispiel sind die Sprachen und Kulturen des Vorderen Orients (Hebräisch, Aramäisch), die im Zuge der Überlieferung biblischer Texte erst ins Lateinische übersetzt wurden. Lexikografen werden europäische wie außereuropäische Spuren im eigenen Wortschatz aber nur entdecken, wo sie sie für möglich halten. 
Der innereuropäische Sprachenzusammenhang gleicht wohl weniger einer zentralistisch auf das Latein bezogenen Struktur, sondern einem dezentralen Netz aus kleineren Clustern von Sprachen, die ihre Clusterzugehörigkeit im Laufe der Geschichte verschieben und wechseln und die in mehreren Clustern aufnehmend und abgebend mitspielen. Das Cluster-Modell lässt zudem weit eher als das lateinzentrierte Modell die Erkenntnis zu, dass Europas Außengrenzen nicht scharf zu ziehen sind.

Historische Vergleiche zwischen je zwei oder wenig mehr Sprachen sind seit Jahrhunderten vielfältig angestellt worden, sicher nicht immer mit dem Ziel, gesamteuropäische Gemeinsamkeiten festzustellen. Insgesamt muss aus diesen Vergleichen aber gefolgert werden, dass, insbesondere für die nachhumanistische Zeit, das Fundament des Lateins oft eine nur mittelbare Funktion erfüllte und dass benachbarte oder politisch eng, z. T. in Diglossiesituationen verbundene Sprachen einander unmittelbarer und stärker beeinflussten. Z.B. wurden bis ins 19. Jahrhundert viele deutsche Wörter ins Dänische, Schwedische und Norwegische entlehnt. So gelangten lateinische und griechische Wörter über das Deutsche, das Englische und das Französische in die skandinavischen Sprachen (Malmgren 2005). Die Sprachgeschichten Europas weisen eine Fülle ähnlicher Beispiele auf.

In der zweiten Phase des Zusammenspiels von Sprachgeschichte und Wörterbuch erreicht die Diskussion um die Leitvarietät die Ebene der Dokumentation z. B. zu Zwecken der Schule und des Unterrichts - dies ist die Stunde der Wörterbücher, aber auch der Sprachakademien, -institute und anderer Expertengesellschaften. Es fällt auf, dass all diese Autoritäten sich stets auf einige bestimmte, nie auf sämtliche Aspekte der Leitvarietät konzentrierten. In einem Land steht die Orthografie im Fokus, in einem anderen die Aussprache, es werden Lehn- und Fremdwörter von einheimischen abgegrenzt oder es wird das Pro und Contra einer mündlichen (z.B. in Skandinavien) gegenüber einer schriftlichen Leitvarietät (z.B. in Deutschland) diskutiert. Je nachdem, für welche dominanten Eigenschaften der Leitvarietät man sich entschied, wurden ältere Wörterbücher umgeschrieben, angereichert oder in Teilen überarbeitet. Je länger aber die Fertigstellung eines Wörterbuchs dauerte, desto größer wurde der Einfluss der sie begleitenden Expertendiskussion und desto mehr Eigenschaften der Leitvarietät sollten im Wörterbuch festgehalten werden. Und deshalb findet man beides: Wörterbücher, deren Intention die Deskription eines Sprachstandards ist, die von der Gesellschaft aber zugleich als normsetzende Sprachautorität wahrgenommen und benutzt werden, und Wörterbücher, die sich laut ihrer Vorworte als maßgebliche Autoritäten verstanden, die faktisch den Sprachgebrauch aber ,nur ' beschrieben, der in dem ihnen zugrundeliegenden Korpus zu erkennen war. Umso entscheidender sind dann natürlich die Kriterien der Textauswahl. Die zweite Phase ist zeitlich um die Aufklärung herum anzusiedeln.

Die dritte und letzte Phase ist die der Konsolidierung des Sprachstandards. Wörterbücher sind jetzt eine von mehreren Möglichkeiten der Dokumentation 
des Standards, aber doch ein für diesen Zweck herausragendes Medium, das oft eine symbolische Bedeutung für die betreffende Kultur hat. Das Wörterbuch soll nun die weitere Entwicklung des Standards ,mitprotokollieren' und je aktuell fixieren, so dass Ergänzungsbände und Neuauflagen wichtig werden. Für die meisten europäischen Sprachen begann diese Phase zu Beginn des 20. Jahrhunderts und erfuhr eine Intensivierung nach dem zweiten Weltkrieg. Am Ende des Prozesses verwandeln sich Wörterbücher vom Schatzhaus zum Datenspeicher. Vielleicht kann man die riesigen, lange Bearbeitungszeit beanspruchenden und deshalb so immens heterogenen Wörterbücher Europas besser verstehen, wenn man sie auf die beiden letzen der drei genannten Phasen bezieht.

Besonders eng war das Zusammenspiel von Sprachgeschichte, allgemeiner Geschichte und Wörterbüchern in der Zeit der Nationalbewegungen. In der politischen Situation Europas nach Ende der Napoleonischen Herrschaft liegt der Schlüssel für den Erfolg der von den Brüdern Grimm, dem dänischen Sprachwissenschaftler Rasmus Rask und dem Engländer William Jones entwickelten ,SuperIdeologie', in der die Konstruktion einer Nation ganz wesentlich mithilfe der Nationalsprache und hier v.a. deren Alter, Altehrwürdigkeit und geschichtlicher Erforschung vorgenommen wurde. Diese ,Super-Ideologie', in der Sprachwissenschaft, Politik, kulturelle Identität und z.T. auch romantische Schwärmerei zusammengeführt wurde, beschäftigte die Intellektuellenkreise jedes europäischen Landes, unterschiedlich waren lediglich der Entwicklungsgrad einer Nationalbzw. Standardsprache und die daraus resultierende Funktion der Sprachforschung und die jeweilige realpolitische Situation: In Deutschland, den Niederlanden und in Schweden ging es beispielweise um Erforschung und geschichtliche Absicherung einer seinerzeit relativ entwickelten Nationalsprache. In anderen Ländern hingegen musste die historische Sprachforschung das erwünschte Band sprachlicher Einigung erst konstituieren oder gar konstruieren, z. B. in Norwegen. Dass die historische Sprachforschung des 19. Jahrhunderts beides konnte ${ }^{24}$ und darüber hinaus an politische und pädagogische Diskurse anschlussfähig war, begründete ihren großen und europaweiten Erfolg.

Die Bedeutung der Nationalbewegungen im 19. und 20. Jahrhundert für die großen Sprachwörterbücher des 19. Jahrhunderts und der damit oft vorbereitend verbundenen, aber auch nachträglich stützenden Sprachnationalismen Europas können kaum hoch genug eingeschätzt werden. Gardt (1999a, 2000) hat darauf

24 Es gab allerdings auch Misserfolge: Der aus demselben romantischen Diskurs wie die Nationalsprachbewegungen erwachsene Pan-Skandinavismus in der Mitte des 19. Jahrhunderts konnte kaum sprachwissenschaftliche Unterstützung beanspruchen: Die gemeinsame nordische Ursprache (Altnordisch) an die Stelle von Dänisch, Schwedisch, Norwegisch, Isländisch und Färoisch zu setzen, konnte kaum gelingen; die Diskussionen der skandinavischen Sprachwissenschaftler drehten sich denn auch nicht um pan-skandinavisches Wörterbuch und pan-skandinavische Grammatik, sondern ,nur' um orthografische und phonetische Fragen. Siehe Monsson 2005, Vannebo 2005, Venås 2005. 
aufmerksam gemacht, dass der (frühe) Sprachpatriotismus bzw. der (spätere) Sprachnationalismus mit seinen Übereinander-Blendungen von Sprache und Nation auf eine historisch-genetische Sprachauffassung angewiesen war, in der die Sprache als prinzipiell von sprachhandelnden Individuen unabhängige, autonome (hypostasierte) Größe mit einer eigenen Entwicklungslogik verstanden wurde. Die genetische Auffassung der eigenen Sprache setzt aber voraus, dass ihre Verwurzelung in der indoeuropäischen Sprachenfamilie anerkannt wird, was im 19. Jahrhundert zu einer abgestuften Bewertung führte: An oberster Stelle der Wertehierarchie stand die je eigene Sprache, danach kamen alle flektierenden, d.h. die indoeuropäischen Sprachen und am unteren Ende befanden sich alle übrigen bekannten Sprachen. Mit Gardt (1999a, 106) ist also v.a. im Diskurs der sprachvergleichenden Wissenschaft eher von einer eurozentrischen denn von einer nationalistischen Sprachauffassung auszugehen. Nationalchauvinistische Abgrenzungen innerhalb Europas, sofern sie sprachlich argumentierten, sind denn auch nicht von Philologen und Sprachwissenschaftlern, sondern am ehesten von linguistischen Laien belegt.

Tatsächlich lassen sich die ausführlichen etymologisch-sprachvergleichenden Artikelköpfe im Deutschen Wörterbuch der Brüder Grimm, die einer Rezeption durch das ,einfache Volk' hartnäckig widerstanden, als tausendfach wiederholte Demonstration der Tatsache verstehen, dass das Deutsche strukturell und lexikalisch in die indoeuropäische Sprachenfamilie eingewoben ist. Die SchatzhausMetapher hingegen betonte das wertvolle, besondere Eigene - gegenüber ,dem Volk' wohlgemerkt.

\section{8 Ähnliche Schreibweisen und Lexikon-Stile - enthalten europäische Lexika auch ähnliche Wissensinhalte?}

Wenn hier darüber nachgedacht wird, ob Europa in seinen Wörterbüchern und Enzyklopädien einen konturierten, Wissensraum' darstellt, dann muss auch nach Übereinstimmungen der Inhalte bzw. Informationen v.a. der Enzyklopädien gefragt werden. Denn wenn es die oben erläuterten zahlreiche Gemeinsamkeiten und Wechselwirkungen unter den europäischen Kulturen gibt, dann könnten auch alle den gleichen Wissensstock teilen. Die Frage ist schwer zu beantworten und die Beiträge dieses Bands können dies nicht leisten. Aber es sollen an dieser Stelle ein paar Hinweise zum Forschungsstand und zu möglichen methodischen Ansätzen, mit denen man sich der Frage nach den Inhalten nähern könnte, gegeben werden.

Zunächst existieren Aufsätze z. B. aus Musikwissenschaft, Rechtswissenschaft, Physik, die historische allgemeine wie spezielle Enzyklopädien als eine von mehreren wissenschafts- und fachgeschichtlichen Quellengattungen analysieren. Die folgenden beiden Arbeiten haben interessanterweise enzyklopädische Werke zur Musik und zur Physik des 18. Jahrhunderts aus unterschiedlichen Sprachnationen miteinander verglichen. 
Anselm Gerhard (1998) untersuchte französische und deutsche Enzyklopädien des 18. Jahrhunderts im Hinblick auf die Präsentation des Wissens über Musik, und zwar sowohl spezielle Musik- wie allgemeine Lexika, darunter auch Einträge der großen französischen Enzyklopädie aus der Feder Jean Jacques Rousseaus. Gerhard konnte als eine transnationale Tendenz feststellen, dass sich das Wissensschema Musik weg von einer mehr technisch orientierten Musiktheorie und vom Gesichtspunkt des ausführenden Musikers hin zu einem mehr ästhetischen Verständnis von Musik als einer neben anderen Kunstgattungen entwickelte; in diesem Verständnis steht der Komponist höher als der Musiker. Die weitgehende Übereinstimmung des französischen und des deutschen Wissens über Musik kann auf ein enges Netz wechselseitiger Einflüsse, von der Argumentation bis hin zu Umschreibungen der fremdsprachigen Vorlage und sogar plagiierendem Abschreiben, zurückgeführt werden.

Andreas Kleinert (1998) untersuchte ein bestimmtes deutsches enzyklopädisches Wörterbuch zur Physik, ebenfalls aus dem 18. Jahrundert. Dessen Autor folgte zwar einem französischem Vorbild, verweigerte jedoch eine schlichte Übersetzung, weil das Original seines Erachtens die „neuern Entdeckungen der Engländer und Deutschen" nicht kenne und bei seinem gewohnten französischen, aber veralteten System stehen bleibe (ebd. 130). Konsequenterweise entstand keine Übersetzung, sondern ein ganz neues Physiklexikon, in dem das Wissen von mindestens zehn Physikern aus verschiedenen europäischen Ländern und Nordamerika zusammengetragen wurde. Bemerkenswert an diesem Beispiel ist die ausdrückliche Forderung des Enzyklopäden, physikalisches Wissen müsse europäisch, besser noch weltweit sein, soweit die damalige, Welt' sprachlich zugänglich war.

Die über-nationale Orientierung innerhalb der Physik ist noch plausibler als die der Musik, denn die Existenz einer Naturwissenschaft hängt von einer scientific community mit einer gemeinsamen Sprache und geteilten Kommunikationsforen ab. Musik hingegen weist auch regionale oder nationale Praxen auf, die mit den musikwissenschaftlichen Diskursen in keinem Zusammenhang stehen müssen. Es kann nach diesen Beispielen wohl angenommen werden, dass das enzyklopädische Wissen zumindest des 18. Jahrhunderts in keiner Weise national begrenzt oder spezifisch war.

Was bei wissenschaftshistorischen Arbeiten wie Gerhard (1998) und Kleinert (1998) kaum in den Blick genommen werden kann, ist die Frage der sprachlichen Formung der ,Wissensinhalte - diese Bezeichnung unterstellt fälschlicherweise, dass es einen Inhalt unabhängig von seiner Kodierung durch Sprache, Schrift und Bild gäbe und unabhängig von Entscheidungen der Enzyklopäden, welches die wissenswerten Charakteristika eines Gegenstands seien und welche nicht. Der europäische oder globale Vergleich von (Ausschnitten von) Wissenssystemen müsste methodisch bei der Untrennbarkeit von Darstellungsform und Wissensinhalt ansetzen, also so etwas wie Lexikonstile berücksichtigen. Wie so etwas aussehen und zu welchen Ergebnissen es führen könnte, sei an einem kleinen exemplarischen Vergleich der aktuellen Auflagen der Encyclopaedia Britannica (EB) und der Brock- 
haus Enzyklopädie veranschaulicht. Dazu wurden in beiden Lexika einige Stichworteinträge ausgewählt, die mehr und andere Gegenstände abdecken sollten als rein wissenschaftliche, nämlich auch soziale, technische, institutionelle und mediale. Ferner ist die Behandlung von Themen mit nicht-europäischem Hintergrund interessant sowie die Anlage personenbezogener Informationen. ${ }^{25}$ Es handelt sich um folgende Einträge:

Buch/book, Krokodillcrocodile, Schach/chess, Kartelmap, Mittelalter/middle ages, Geld/ money, Nachbar/neighbour, Geburtshilfelobstetrics; midwifery, Stabl(herstellung)/(steel (making), Strukturallismus/structuralism. - Descartes, Leibniz, Newton, Christian Wolff.

Es ist noch vorauszuschicken, dass die Brockhaus Enzyklopädie in gedruckter Version vorliegt, während die Britannica in einer Online-Version vorliegt, die gründlich an hypertextuelle Strukturen angepasst ist. Man muss hier mediale Besonderheiten also ausklammern, wo es um die Frage nach einer möglichen nationalen Spezifik geht.

Die Analyse der o.g. Einträge ließ zwei auffallende Unterschiede zwischen den Enzyklopädien zutage treten - Unterschiede im Stil, die Unterschiede in der Wahrnehmung, der kognitiven Repräsentanz der Inhalte konstituieren.

Die erste Differenz betrifft die explizit gemachte Rolle und den Einfluss von Sprache auf die Wissenskonstruktion. zu Beginn eines jedes Stichworteintrags gibt der Brockhaus, wo immer sinnvoll, etymologische Informationen und/oder Synonyme an, um zu begründen, welcher der Ausdrücke der gebräuchliche ist und welcher nicht. Die definitorischen Erläuterungen sind, besonders im ersten Satz, wörterbuchähnlich. Sogar unterschiedliche Lesarten einer Stichwortform werden nach lexikografischen Konventionen genannt und nummeriert, auch wenn nur eine der Lesarten ein enzyklopädisch relevanter Gegenstand ist. Z. B. wird s. v. Karte als erste Lesart ,Postkarte‘ verzeichnet, obwohl zu Postkarten keine Informationen gegeben werden - weil sie nicht, wissenswert' sind? Folgende Formulierungen sind typisch für den Brockhaus; sie zeigen, dass sich seine Autoren dessen bewusst sind, dass man nur durch die Sprache hindurch, nie ohne sie auf die Dinge blicken kann:

allgemeine Bezeichnung für ...; spricht man von ... (wenn ...); werden als ... bezeichnet

Die Britannica konzentriert sich deutlich auf den Begriff, d.h. auf die Inhaltsseite eines Terminus, doch scheinen sich ihre Autoren in einigen selteneren Fällen genötigt zu fühlen, die Bezeichnungen selbst zu kommentieren:

The tedious and somewhat abstract statements resulting from attempts to formulate precise definitions of maps and charts are more likely to confuse than to clarify. The words map, chart, and plat are used somewhat interchangeably. The connotations of use, however, are distinctive: charts for navigation purposes ... (EB 2002, s.v. map)

25 Ich beschränke mich hier bewusst auf berühmte Männer. Die enzyklopädische Behandlung von Frauen zu untersuchen wäre eine eigene, anders anzulegende Aufgabe. 
M.a.W.: Die leidige terminologische Frage wird so rasch wie möglich erledigt, so dass Autor wie Leser zum ,Eigentlichen', der Beschreibung von Kartographie und Landkartenherstellung kommen können.

Die zweite deutliche Differenz betrifft die Rolle und den Status individuellbiografischer Aspekte in den Erläuterungen eines Themas. Der Brockhaus bietet viel mehr Personennamen, z. B. die der Erfinder der Stahlherstellung, von Kartographen und Geburtshelfern, Namen berühmter Schachspieler usw. Zudem werden alle Namen typografisch mittels Kapitälchen hervorgehoben. Dies gilt insbesondere für historische Personen, und zwar in einer Weise, dass man von der (tendenziellen) Personifizierung historischer Konzepte sprechen könnte.

Die Britannica entwirft ein Thema allgemeiner; Kern und Randgebiete sind klar getrennt und jede Einzelheit ist dem Thema als solchem ein- und untergeordnet. Entsprechend selten werden Personennamen genannt, die gelegentlich sogar wie dekorativ wirken. So ist es z. B. kaum notwendig, allerdings anschaulich, Swifts Erwähnung von Landkarten ausführlich zu zitieren, wenn der Stand der Kartographie zu seiner Zeit dargestellt werden soll:

As man explored and recorded his environment, the quality of his maps and charts improved. These lines of Jonathan Swift were inspired by early maps:

So geographers, in Afric maps,

With savage pictures fill their gaps,

And o'er unhabitable downs

Place elephants for want of towns. (EB 2002)

Offensichtlich ordnen Brockhaus und Britannica Personen und ihre individuellen Kulturleistungen anders ein; dies wird unterstrichen durch die Art, in der berühmte Männer dargestellt werden. Alle Einträge dazu, unabhängig von der nationalen Herkunft des Betreffenden, sind im Brockhaus länger als in der Britannica. Dies liegt daran, dass Personenartikel in der Britannica üblicherweise durch viele Querverweise mit langen und eingehenden Sachartikeln (z. B. history of philosophy, history of physics) verknüpft sind. Personen erscheinen fast völlig integriert in Entwicklungen und Bewegungen. Dem - gedruckten - Brockhaus fehlt diese enge Verknüpfung. Dennoch ist diese Besonderheit nicht nur medial zu erklären. Der Brockhaus informiert seine Leser regelmäßig über die soziale Herkunft der Berühmtheiten - eine Information, die in den untersuchten Britannica-Artikeln nicht zu finden war. Deutschsprachige Nutzer erfahren, dass Leibniz der Sohn eines Rechtsanwalts und Professors, Newton ein Bauerssohn und Descartes adliger Herkunft war. Für englischsprachige Nutzer der weltweit rezipierten Britannica steht die individuelle Leistung historischer Persönlichkeiten potenziell also nicht in irgendeinem Zusammenhang mit ihrer sozialen Herkunft; Leistung erscheint von vornherein unabhängig.

Das Personifizieren und die Betonung des Biografischen im Brockhaus könnte in der Tat ein deutsches Charakteristikum darstellen und nicht nur ein Spezifikum des Verlags oder des Produkts. Meike Wiese (2010) hat in ihrer Untersuchung 
eines Musiklexikons des frühen 18. Jahrhunderts festgestellt, dass dessen Autor ein französisches und ältere deutsche Vorbilder kompilieren sollte, dass er die Vorlagen aber systematisch um sowohl biografische wie terminologische Aspekte anreicherte und dies gegen den Wunsch des auf rasche Fertigstellung drängenden und auf geringstmöglichen Umfang bedachten Verlegers tat. Auch wenn diese genannten Belege noch keine allgemeinen Aussagen rechtfertigen, so können sie künftiger Forschung doch eine ernstzunehmende Hypothese liefern: Informationsauswahl und Darstellungsstile großer Enzyklopädien reflektieren sogar im globalen Zeitalter nationale Traditionen und tragen wesentlich zur Konstruktion nationalkultureller Varianten eines globalen Wissens bei.

Der exemplarische Vergleich von Einträgen der Britannica und des Brockhaus brachte aber auch viele Gemeinsamkeiten und Ähnlichkeiten der Wissensinhalte zutage. Das Mittelalter und der Strukturalismus, die Bedrohung der Krokodile durch den Menschen und die Bezeugung früher kultureller Errungenschaften der chinesischen, arabischen, ägyptischen und anderer nicht-europäischer Kulturen werden weitgehend übereinstimmend behandelt. Wo leichte Unterschiede zu erkennen sind, dürften sie eher aus anderen, kontingenteren als aus nationalen Ursachen resultieren.

\section{Nationaler, europäischer oder globaler Wissensraum?}

In der Zusammenschau zeigen die in Abschnitt 5 behandelten Aspekte europäischer Wörterbücher und Enzyklopädien insgesamt mehr Belege für als gegen eine europäische Verfasstheit des Wissens. Nur der zuletzt behandelte Aspekt, die inhaltliche Konturierung des Wissens, deutete auf den Einfluss nationaler Traditionen hin. $\mathrm{Ob}$ sich dies bei der Untersuchung der übrigen drei oder vier großen europäischen Traditionen neben der englischen und der deutschen - der französischen, der spanischen, der italienischen, der polnischen - bestätigen würde, ist noch ebenso offen wie die Frage, ob kleinere Länder (z. B. die Niederlande, Österreich, Dänemark, Griechenland, Litauen und viele mehr) sich eher den größeren Traditionen angeschlossen oder ebenfalls spezifische Wissenskonturierungen hervorgebracht haben. Es ist eine beklagenswerte Tatsache, dass die lexikografische wie die enzyklopädische Forschung auf wenige, große 'Sprachen und Nationalkulturen beschränkt ist. Der Einfluss der ,großen' auf den europäischen Wissensraum wird dadurch möglicherweise folgenschwer überschätzt.

Während auf der einen Seite ein europäisch charakterisiertes Netz des Wissens offensichtlich zu existieren scheint, muss man andererseits die globale Reichweite dieses Wissens in Betracht ziehen. Die Fremdsprachenkenntnisse früherer Lexikografen und Enzyklopäden, der wissenschaftliche Diskurs, technische, mediale und ökonomische Bedingungen und historische Entwicklungen - dies alles mag in Gestalt der großen Nachschalgewerke europäischen Ursprungs gewesen sein, doch es 
breitet sich nicht erst in jüngster Zeit über die Welt aus. US-Amerika stellt sich in dieser Perspektive als Multikplikator, nicht als Ausgangspunkt dar. Am Ende kehrt das globalisierte Wissen nach Europa zurück und wird dabei ,glokalisiert ${ }^{\top}-$ die Vielfalt der Wikipedias ${ }^{26}$, die mit z. B. Volapük, Simple English, Saterfriesisch, Obersorbisch, Ladinisch, Limburgisch usw. Nationalsprachlichkeit längst hinter sich gelassen hat, ist dafür ein schlagendes Beispiel.

Die Beschäftigung mit vergleichender Lexikografie(geschichte) zeigt eindrücklich, dass es bei der Hervorbringung von Nachschlagewerken keine kontinuierliche Trennung nationaler Traditionen gibt. Kulturen „fließen vielmehr zusammen" (Trojanov/Hoskoté 2007) und die Lexikografie bzw. Enzyklopädik spielen im Prozess des Zusammenfließens eine herausragende Rolle. Worin diese Rolle genau besteht und wie sie sich im Laufe der Geschichte verändert (hat), ist für ,Wissensgesellschaften' sicherlich eine wichtige Frage. Hinreichende, d.h. systematische Antworten können auch die Beiträge in diesem Band noch nicht liefern. Mögen sie dazu beitragen, Interesse zu stiften und weitere Forschungen anzuregen.

\section{Literatur}

Albert, Claudia (1995). Imitation de la nature? Probleme der Darstellung in der Encyclopédie. In: Eybl, Franz M. et al. (Hgg.). Enzyklopädien der Frühen Neuzeit. Beiträge zu ihrer Forschung. Tübingen: Niemeyer. S.200-214.

Albrecht, Wolfgang (1995). Aufklärerische Selbstreflexion in deutschen Enzyklopädien. In: Eybl; Franz M. et al. (Hgg.). Enzyklopädien der Frühen Neuzeit. Beiträge zu ihrer Forschung. Tübingen: Niemeyer. S.232-254.

d'Alembert, Jean Le Rond (1750/1989). Einleitung zur Enzyklopädie. Discours Préliminaire de l'Encyclopädie. Hrsg. von Günther Mensching. Aus dem Französischen von Annemarie Heins. Revision dieser Übersetzung von Günther Mensching. Frankfurt/M.: Fischer.

Antweiler, Christoph (2009). Heimat Mensch. Was uns alle verbindet. Hamburg: Murmann. Bandur, Markus (2004). Stichwort Musik. zur Problematik der Darstellung von Fachwissen in Enzyklopädien des 18. Jahrhunderts. In: Stammen, Theo/Weber, Wolfgang E.J. (Hgg.). Wissenssicherung, Wissensordnung und Wissensverarbeitung. Das europäische Modell der Enzyklopädien. Berlin: Akademie-Verlag. S.233-244.

Biesterfeld, Hinrich (2004). Enzyklopädie und belles-lettres im arabisch-islamischen Mittelalter. In: Stammen, Theo/Weber, Wolfgang E.J. (Hgg.). Wissenssicherung, Wissensordnung und Wissensverarbeitung. Das europäische Modell der Enzyklopädien. Berlin: Akademie-Verlag. S.71-80.

Brockhaus. Die Enzyklopädie in 24 Bänden (2001). 20. Ausg. Leipzig, Mannheim: F.A. Brockhaus.

Creamer, Thomas B.I. (1991). Chinese Lexicography. In: Hausmann, Franz Josef et al. (Hgg.). Wörterbücher. Ein internationales Handbuch zur Lexikographie. 3 Teilbde. Berlin, New York: de Gruyter. S.2595-2612.

26 Aufgelistet in: www.wikipedia.org. 
Crusca: Vocabolario degli Accademici della Crusca (1612). Florenz.

Darnton, Robert (1993). Glänzende Geschäfte. Die Verbreitung von Diderots Encyclopedie oder wie verkauft man Wissen mit Gewinn? Aus dem Engl. und Franz. von Horst Günther. Berlin: Wagenbach.

Diderot, Denis/d'Alembert, Jean le Rond (1751-1772). Encyclopédie ou Dictionnaire raisonné des sciences, des arts et des métiers. Paris.

Dorn, Nico (2008). Zedlers Universal-Lexicon und das Problem seiner inhaltlichen Erschließung. In: Schneider, Ulrich Johannes (Hg.). Kulturen des Wissens im 18. Jahrhundert. Berlin: de Gruyter. S. 183-190.

Elkar, Rainer S. (1995). Altes Handwerk und ökonomische Enzyklopädie: Zum Spannungsverhältnis zwischen handwerklicher Arbeit und „nützlicher" Aufklärung. In: Eybl, Franz M. et al. (Hgg.). Enzyklopädien der Frühen Neuzeit. Beiträge zu ihrer Forschung. Tübingen: Niemeyer. S.215-231.

Enciclopedia italiana di scienze, lettere ed arti (1929-1937). Rome. 35 volumes.

Encyclopaedia Britannica. De luxe edition. online 2002. (1994-2002).

Engler, Rudolf (2000). Die Accademia della Crusca und die Standardisierung des Italienischen. In: Auroux, Sylvain/Koerner, E.F.K/Niederehe, Hans-Josef /Versteegh, Kees (Hgg.). Geschichte der Sprachwissenschaften. Ein internationales Handbuch zur Entwicklung der Sprachforschung von den Anfängen bis zur Gegenwart. 3 Teilbde. Berlin: de Gruyter. S. 815-827.

Ersch, J.S./Gruber, J.G. (Hgg. 1840/1971). Allgemeine Encyklopädie der Wissenschaften und Künste. Erste Section, A-G, 34. Theil, Nachdruck der Aufl. 1840. Graz.

Eybl, Franz M./Harms, Wolfgang/Krummacher, Hans-Erik/Welzig, Werner (Hgg.). Enzyklopädien der Frühen Neuzeit. Beiträge zu ihrer Forschung. Tübingen: Niemeyer.

Fontius, Martin (1998). Stellen wir die richtigen Fragen zur Enzyklopädiegeschichte? Bemerkungen zu den Forschungen zu Frank A. Kafker. In: Das achtzehnte Jahrhundert 22/1998. S. 139-145.

Gardt, Andreas (1999). Geschichte der Sprachwissenschaft in Deutschland. Vom Mittelalter bis ins 20. Jahrhundert. Berlin: de Gruyter.

Gardt, Andreas (1999a). Sprachpatriotismus und Sprachnationalismus. In: Gardt, Andreas/ Haß-Zumkehr, Ulrike/Roelcke, Thorsten (Hgg.). Sprachgeschichte als Kulturgeschichte. Berlin: de Gruyter. S. 89-113.

Gardt, Andreas (2000): Sprachnationalismus zwischen 1850 und 1945. In: Gardt, Andreas (Hg.): Nation und Sprache. Die Diskussion ihres Verbältnisses in Gegenwart und Geschichte. Berlin: de Gruyter. S.247-271.

Gerhard, Anselm (1998). Die Rolle der Musik in den enzyklopädischen Wörterbüchern des 18. Jahrhunderts. In: Das achtzehnte Jahrhundert 22/1998. S.40-51.

Grimm, Jacob und Wilhelm Grimm (1985). Schriften und Reden. Ausgewählt und herausgegeben von Ludwig Denecke. Stuttgart: reclam.

Hausmann, Franz Josef/Reichmann, Oskar/Wiegand, Herbert Ernst/Zgusta, Ladislav (Hgg. 1989-1991). Wörterbücher. Ein internationales Handbuch zur Lexikographie. 3 Teilbde. Berlin, New York: de Gruyter.

Haß-Zumkehr, Ulrike (1995). Daniel Sanders. Aufgeklärte Germanistik im 19. Jahrhundert. Berlin, New York: de Gruyter.

Haß-Zumkehr, Ulrike (2001). Deutsche Wörterbücher-Brennpunkt von Sprach-und Kulturgeschichte. Berlin: de Gruyter.

Haß-Zumkehr, Ulrike (2004). Hermann Pauls Principien der Sprachgeschichte. Von der ersten zur zweiten Auflage. In: Haßler, Gerda/Volkmann, Gesine (Hgg.): History of Lin- 
guistics in Texts and Concepts/Geschichte der Sprachwissenschaft in Texten und Konzepten. Vol.I. Münster: Nodus. S.277-284.

Haywood, John A. (1991). Arabic Lexicography. In: Hausmann, Franz Josef et al. (Hgg.). Wörterbücher. Ein internationales Handbuch zur Lexikographie. 3 Teilbde. Berlin, New York: de Gruyter. S.2438-2448.

Heming Yong/Jing Peng (2008). Chinese Lexicography. A History from 1046 BC to AD 1911. Oxford: Oxford University Press.

Hohrath, Daniel (2004). Die Beherrschung des Krieges in der Ordnung des Wissens. Zur Konstruktion und Systematik der militairischen Wissenschaften im Zeichen der Aufklärung. In. Stammen, Theo; Wolfgang E.J. Weber (Hgg.). Wissenssicherung, Wissensordnung und Wissensverarbeitung. Das europäische Modell der Enzyklopädien. Berlin: Akademie-Verlag. S.371-386.

Jacoby, Michael (1990). Historische Lexikologie zum nordgermanischen Raum. Lexika als Kultur- und Sprachdokument zwischen Mittelalter und Neuzeit. Wiesbaden: Harrassowitz.

Jansone, Ilga (2003). Entwicklung der lettischen Lexikographie von G. Mancelius bis zu elektronischen Wörterbüchern. Lettische Lexikographie im 17. Jahrhundert. In: Zeitschrift für Literaturwissenschat und Linguistik 129/2003. S.64-95.

Jorio, Marco (2004). Die Geschichte der Enzyklopädie in der Schweiz seit dem 17. Jahrhundert. In: Stammen, Theo/Weber, Wolfgang E.J. (Hgg.). Wissenssicherung, Wissensordnung und Wissensverarbeitung. Das europäische Modell der Enzyklopädien. Berlin: AkademieVerlag. S. 105-117.

Keiderling, Thomas (2009). Von der Querstraße zum Johannisfriedhof. Bibliographisches Institut und F.A. Brockhaus werden zu Grabe getragen. In: Leipziger Blätter 54/2009. S.76-77.

Kiesow, Rainer Maria (2004). Die Ordnung des juridischen Wissens. In: Stammen, Theo/ Weber, Wolfgang E.J. (Hgg). Wissenssicherung, Wissensordnung und Wissensverarbeitung. Das europäische Modell der Enzyklopädien. Berlin: Akademie-Verlag. S. 59-70.

Kirkness, Alan (2011). Wörterbuchschreiber als Wörterbuchbenutzer. Die Lexikographie Jacob Grimms und Wilhelm Grimms im europäischen Kontext. In: Brüder Grimm Gedenken 17/2011. S.208-242.

Kleinert, Andreas (1998). Die deutschsprachigen physikalischen Wörterbücher des 18. Jahrhunderts - Johann Samuel Traugott Gehler und Johann Carl Fischer. In: Das achtzehnte Jahrhundert 22/1998. S. 129-138.

Littré, Émile (1863-1872). Dictionnaire de la langue française. 4 vol. Paris: Hachette.

Malmgren, Sven Göran (2005). The lexicon of the Nordic languages in the 19th century. In: Bandle, Oskar/Braunmueller, Ernst Håkon Jahr/Karker, Allan/Naumann, Hans-Peter/ Teleman, Ulf (Hgg.). The Nordic Languages. An International Handbook of the History of the Nordic Languages. 2 Vols. Berlin, New York: de Gruyter. S. 1443-1453.

Mayrhofer, Manfred (1991). Altiranische Lexikographie. In: Hausmann, Franz Josef et al. (Hgg.). Wörterbücher. Ein internationales Handbuch zur Lexikographie. 3 Teilbde. Berlin, New York: de Gruyter. 2470-2473.

Monnson, Odd (2005). Nationalism and Scandinavism in the development of the Nordic languages in the 19th century. In: Bandle, Oskar/Braunmueller, Ernst Håkon Jahr/Karker, Allan/Naumann, Hans-Peter/Teleman, Ulf (Hgg.). The Nordic Languages. An International Handbook of the History of the Nordic Languages. 2 Vols. Berlin, New York: de Gruyter. S. 1453-1468.

Munske, Horst Haider/Kirkness, Alan (Hrsg 1996). Eurolatein. Das griechische und lateinische Erbe in den europäischen Sprachen. Tübingen 1996. 
Passow, Franz (1819-1823). Handwörterbuch der griechischen Sprache. 1. Auflage. Leipzig: Friedrich Christian Wilhelm Vogel.

Passow, Franz (1812). Über Zweck, Anlage und Ergänzung griechischer Wörterbücher. Berlin: Maurer.

Pörksen, Uwe (1999). Brauchen wir eine vergleichende europäische Sprachgeschichte? Latein als Hintergrund und Untergrund unserer Wissenschaftssprache. In: Wiegand, Herbert Ernst (Hg.). Sprache und Sprachen in den Wissenschaften. Geschichte und Gegenwart. Festschrift für Walter de Gruyter \& Co. anläßlich einer 250jährigen Verlagstradition. Berlin u. a.: de Gruyter. S.638-667.

Remenyi, Maria (2008). ,Popularisierung' und, Wissenschaft' - ein Gegensatz? Die mathematischen Wissenschaften und ihre Vermittlung im 18. Jahrhundert. In: Schneider, Ulrich Johannes (Hg.). Kulturen des Wissens im 18. Jahrhundert. Berlin: de Gruyter. S.347-354.

Schmalstieg, William R. (1991). Lexicography of the Baltic Languages I: Lithuanian, Old Prussian. In: Hausmann, Franz Josef et al. (Hgg.). Wörterbücher. Ein internationales Handbuch zur Lexikographie. 3 Teilbde. Berlin, New York: de Gruyter. S.2351-2354.

Schmid, WolfgangP. (1991). Die Lexikographie der baltischen Sprachen II: Lettisch. In: Hausmann, Franz Josef et al. (Hgg.). Wörterbücher. Ein internationales Handbuch zur Lexikographie. 3 Teilbde. Berlin, New York: de Gruyter. S.2354-2361.

Schmidt-Biggemann, Wilhelm (1995). Enzyklopädie und Philosophia perennis. In: Eybl, Franz M. et al. (Hgg. 1995). Enzyklopädien der Frühen Neuzeit. Beiträge zu ihrer Forschung. Tübingen: Niemeyer. S. 1-18.

Schneider, Ulrich Johannes (2004). Die Konstruktion des allgemeinen Wissens in Zedlers Universal-Lexicon. In: Stammen, Theo/Weber, Wolfgang E.J. (Hgg.). Wissenssicherung, Wissensordnung und Wissensverarbeitung. Das europäische Modell der Enzyklopädien. Berlin: Akademie-Verlag. S. 81-101.

Schneider, Ulrich Johannes (Hg. 2008). Kulturen des Wissens im 18. Jahrhundert. Berlin: de Gruyter.

Schneider, Ulrich Johannes (2008b). Enzyklopädien des 18. Jahrhunderts. Einführung [in die Sektion, UH]. In: Schneider, Ulrich Johannes (Hg.). Kulturen des Wissens im 18. Jahrhundert. Berlin: de Gruyter. S.159-162.

Schneider, Ulrich Johannes (2008c). Der Aufbau der Wissenswelt. Eine phänotypische Beschreibung enzyklopädischer Literatur. In: Schneider, Ulrich Johannes (Hg.). Kulturen des Wissens im 18. Jahrhundert. Berlin: de Gruyter. S. 81-100.

Seifert, Hans-Ulrich (2008). Krünitz online. Planung und Realisierung der digitalen Ausgabe von Johann Georg Krünitz' Ökonomisch-technologischer Enzyklopädie. In: Schneider, Ulrich Johannes (Hg.). Kulturen des Wissens im 18. Jahrhundert. Berlin: de Gruyter. S. 173-182.

Simpson, John (2004). Will the Oxford English Dictionary be more, European' after its first comprehensive revision since its first edition of 1884-1928? In: Mmiscelánea. A Journal of English and American studies 29/2004. S. 59-74.

Stammen, Theo; Wolfgang E.J. Weber (Hgg. 2004). Wissenssicherung, Wissensordnung und Wissensverarbeitung. Das europäische Modell der Enzyklopädien. Berlin: Akademie-Verlag.

Thum, Bernd (2009). Geisteswissenschaften und Technik auf dem Weg zu neuen Wissensräumen. In: Maaß, Jürgen/Thum, Bernd (Hgg.). Deutsche Hochschulen im Dialog mit der arabischen Welt. Beiträge zur Tagung des Wissenschaftlichen Initiativkreises Kultur und Außenpolitik (WIKA), Karlsruhe, 19. und 20. Juli 2007. Karlsruhe: Universitätsverlag. S.75-93. 
Trojanov, Ilja/Hoskoté, Ranjit (2007). Kampfabsage. Kulturen bekämpfen sich nicht-sie fließen zusammen. Aus d. Engl. von Heike Schlatterer. o. O.: Blessing.

Vannebo, Kjell Ivar (2005). The impact of education and literacy on language development in the 19th century. In: Bandle, Oskar/Braunmueller, Ernst Håkon Jahr/Karker, Allan/ Naumann, Hans-Peter/Teleman, Ulf (Hgg.). The Nordic Languages. An International Handbook of the History of the Nordic Languages. 2 Vols. Berlin, New York: de Gruyter. S. 1397-1406.

Venås, Kjell (2005). General tendencies in Nordic language cultivation and language planning. In: Bandle, Oskar/Braunmueller, Ernst Håkon Jahr/Karker, Allan/Naumann, HansPeter/Teleman, Ulf (Hgg.). The Nordic Languages. An International Handbook of the History of the Nordic Languages. 2 Vols. Berlin, New York: de Gruyter. S. 2013-2024.

Wiese, Meike (2010). Zur lexikografischen Methodik eines Musiklexikons von 1732 im europäischen Kontext. Schriftliche Hausarbeit im Rahmen der Ersten Staatsprüfung für das Lehramt an Gymnasien und Gesamtschulen. Universität Duisburg-Essen (unveröff. Ms.).

Wölfflin, Eduard (1893). Plan zur Begründung eines Thesaurus linguae latinae. In: Archiv für lateinische Lexikographie und Grammatik 8/1893. S.621-625.

Wölfflin, Eduard. (Hg. 1884-1908). Archiv für lateinische Lexikographie und Grammatik Bd. 1-16.

Zgusta, Ladislav (1991). Jacob Grimm's Deutsches Wörterbuch and other historical dictionaries of the $19^{\text {th }}$ century (Dvitiyaikakosyam). In: Kirkness, Alan, Peter Kühn, Herbert E. Wiegand (Hgg.). Studien zum Deutschen Wörterbuch von Jacob Grimm und Wilhelm Grimm. Bd.II. Tübingen: Niemeyer. S.595-626.

Internet-Quellen mit einschlägigen weiterführenden Informationen, v.a. zu Digitalisierungen historischer Sprach- und Sachlexika, soweit sie nicht in den einzelnen Beiträgen dieses Bands aufgeführt sind:

http://enzyklopaedie.uni-trier.de/ (4.8.2009)

http://www.zedler-lexikon.de (24.9.2010)

http://portail.atilf.fr/encyclopedie/index.htm (24.9.010) 


\title{
Einführung in den Band, samt eines Versuchs über die Frage, ob Europa als 'Wissensraum' verstanden werden kann
}

\author{
Haß, Ulrike
}

Dieser Text wird über DuEPublico, dem Dokumenten- und Publikationsserver der Universität Duisburg-Essen, zur Verfügung gestellt.

Die hier veröffentlichte Version der E-Publikation kann von einer eventuell ebenfalls veröffentlichten Verlagsversion abweichen.

DOI: https://doi.org/10.1515/9783110241112.1

URN: urn:nbn:de:hbz:464-20190424-141052-4

Link: https://duepublico.uni-duisburg-essen.de:443/servlets/DocumentServlet?id=48640

Rechtliche Vermerke:

Ulrike Haß dankt dem De Gruyter Verlag für die freundliche Genehmigung, diesen Text in der Verlagsversion online veröffentlichen zu dürfen.

Quelle: In: Haß, Ulrike (Hg.): Große Lexika und Wörterbücher Europas. Europäische Enzyklopädien und Wörterbücher in historischen Porträts. Berlin: de Gruyter, 2011, S. 1-49. - ISBN 978-3-11-019363-3 - e-ISBN 978-3-11-024111-2 